\title{
WestVirginiaUniversity
}

THE RESEARCH REPOSITORY @ WVU

Graduate Theses, Dissertations, and Problem Reports

2013

\section{Adult Characteristics Associated With Gender-Typed Toy Ratings}

Rachel R. Stoiko

West Virginia University

Follow this and additional works at: https://researchrepository.wvu.edu/etd

\section{Recommended Citation}

Stoiko, Rachel R., "Adult Characteristics Associated With Gender-Typed Toy Ratings" (2013). Graduate Theses, Dissertations, and Problem Reports. 405.

https://researchrepository.wvu.edu/etd/405

This Thesis is protected by copyright and/or related rights. It has been brought to you by the The Research Repository @ WVU with permission from the rights-holder(s). You are free to use this Thesis in any way that is permitted by the copyright and related rights legislation that applies to your use. For other uses you must obtain permission from the rights-holder(s) directly, unless additional rights are indicated by a Creative Commons license in the record and/ or on the work itself. This Thesis has been accepted for inclusion in WVU Graduate Theses, Dissertations, and Problem Reports collection by an authorized administrator of The Research Repository @ WVU. For more information, please contact researchrepository@mail.wvu.edu. 


\title{
Adult Characteristics Associated With \\ Gender-Typed Toy Ratings \\ Rachel R. Stoiko
}

\section{Thesis submitted to the Eberly College of Arts and Sciences at West Virginia University in partial fulfillment of the requirements for the degree of \\ Master of Science in Life-Span Developmental Psychology}

\author{
Katherine Karraker, Ph.D, Chair \\ Natalie Shook, Ph.D \\ JoNell Strough, Ph.D
}

Department of Psychology

Morgantown, WV

2012

Keywords: Gender development; parenting; college students; gender attitudes; toys 


\section{ABSTRACT \\ Adult Characteristics Associated With Gender-Typed Toy Ratings}

\section{Rachel R. Stoiko}

The toys with which children play shape their development in several domains (TrawickSmith, Russell, \& Swaminathan, 2011). Exclusive or primary play with gender-typed toys may limit children's development, because toys considered appropriate for boys, girls, or both have different characteristics (Blakemore \& Centers, 2005; Serbin \& Connor, 1979). Especially in infancy and early childhood, children's toy play is affected by adults (parent and nonparent), who may differentially provide access to and/or reinforce play with different toys (Kane, 2006). The variability in adults' attitudes regarding the gender-appropriateness of toys is not wellunderstood.

The purpose of this study was to examine the relations between nonparent adults' attitudes about the gender-appropriateness of toys and other beliefs and attitudes. For a sample of 417 nonparent college students $(\mathrm{N}=417)$, several dimensions of participants' gender belief systems, including hostile sexism, benevolent sexism, neosexism, and beliefs about homosexuality, including homonegativity and beliefs about the etiology of homosexuality, were related to their gender-typed ratings of toys. Male participants rated toys in a more gendertyped way, and female-stereotypical toys were rated in a more gender-typed way than malestereotypical toys. This research contributes to knowledge about motivations for adults' socialization of gendered behavior in children. 


\section{TABLE OF CONTENTS}

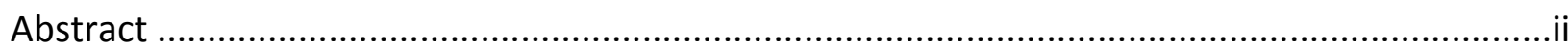

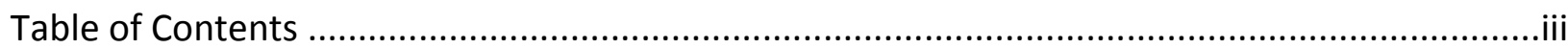

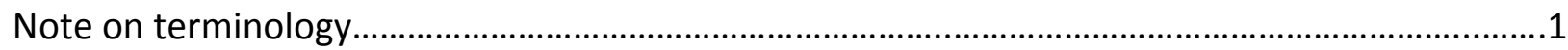

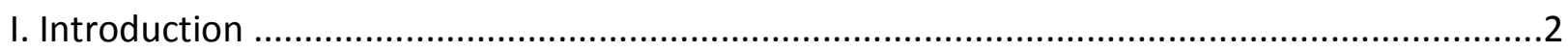

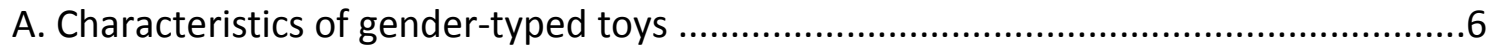

B. Children's play with gender-typed toys.................................................................

C. Development of children's gender-typed toy preferences.....................................9

D. Adult influences children's gender-typed toy preferences....................................10

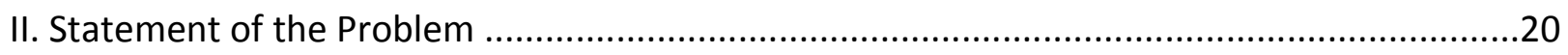

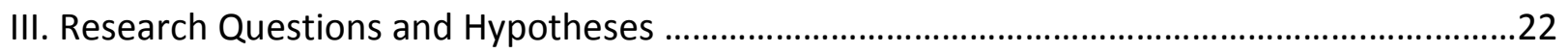

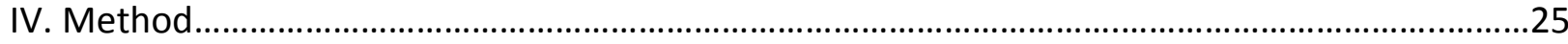

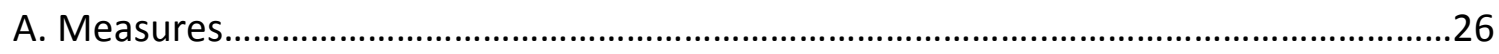

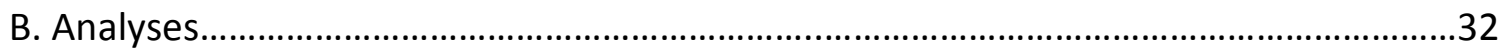

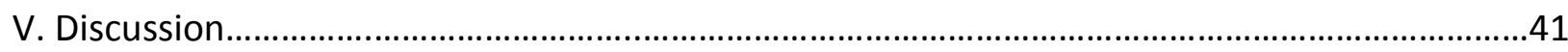

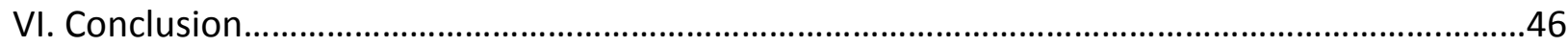

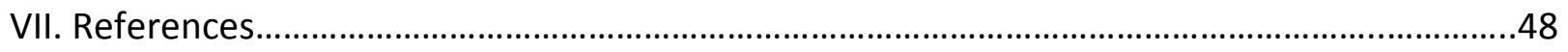



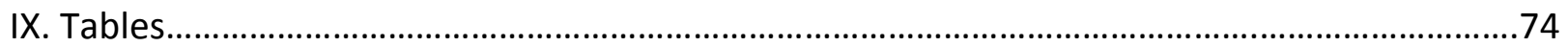

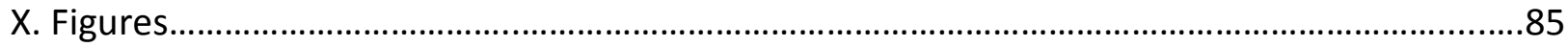




\section{NOTE ON TERMINOLOGY}

The terms "sex" and "gender" are often used interchangeably or in unclear ways.

Drawing on Unger's (1979) classic definitions, "sex" will be used to describe male and female individuals and their biological features, and "gender" will be used when referring to nonphysiological, and therefore presumably more culturally-influenced, behaviors, attitudes, beliefs, and preferences. Studies in this area refer to both sex-typed toys and gender-typed toys; the latter terminology was chosen because beliefs and assumptions about these toys seem to be based on nonphysiological considerations. 


\section{Introduction}

The nature versus nurture debate has always been central to developmental psychology, including the study of gender development. A recent attempt to reconcile this conceptual split is the application of Sherman's (1967) Bent Twig Theory to gender development (Doyle, Voyer, \& Cherney, 2012). This theory, based on the saying, "As the twig is bent, so the tree will grow" suggests that small biological differences early in life may become exacerbated through environmental responses to those differences. The key question within such a framework is no longer, "Are gender differences due to nature or nurture," but rather, "What environmental features interact with biology to produce observed outcomes?" One major environmental feature that is important for young children's gender development is the influence of parents and other adults.

Many parents report ways that they both actively and passively shape their children's gender development, and their strategies for doing so include encouraging both gender-role conformity and nonconformity. These strategies vary based on the context, the specific behavior or trait, and the characteristics of both the child and the parent, including their sexes (Kane, 2006). Parents' choice of strategy also depends on other beliefs that they hold. One set of beliefs that Kane (2006) found to influence parents' gender socialization strategies related to their fear of children becoming homosexual.

Nonparents also are important agents of children's gender socialization. Nonparents serving in many roles have beliefs and attitudes and exhibit behavior that have an impact on children's developing traits, interests, and gender schema. Important nonparents include teachers (Bigler, 1995), coaches (Leaper \& Friedman, 2007), and child care workers (Chick, Heilman-Houser, \& Hunter, 2002). 
Parents, on average, have reported believing that children who show cross-gender behavior are more likely to have poor psychological adjustment and show more homosexual behavior in adulthood (Sandnabba \& Ahlberg, 1999). On the other hand, parents also report that they encourage some cross-gender behavior, traits, or interests, especially for daughters (Kane, 2006).

One specific way in which parents' beliefs and actions shape their children's development, including gender development, is through their choice of toys for their children. Play with toys has been demonstrated to play an important role in preschool children's development in several different domains, such as intellectual, creative, and social development (Trawick-Smith, Russell, \& Swaminathan, 2011). Gender-typed toys, or toys that are considered more appropriate or exclusively appropriate for one gender over the other, have different characteristics and lead to the development of different skills (Blakemore \& Centers, 2005; Serbin \& Connor, 1979). The gender gap in certain skills, interests, and eventually careers that is observed later in the lifespan may be perpetuated through children's toy play along exclusively or mostly gender-typed lines (Cherney, 2008; Tracy, 1987), as predicted by the Bent Twig Theory.

Additionally, play with gender-typed toys is part of the formation of children's gender schemas, their beliefs about the attitudes, interests, abilities, and roles associated with each gender (Caldera \& Sciaraffa, 1998). Playing with a range of toys, instead of only those associated with their own gender, gives children an opportunity to develop a broad range of skills and preferences, which may help reduce gender inequality later in adulthood (Leaper, 2000). 
Parents and other adults are key to the development of children's gender-typed toy preferences. Adults exert direct influence by purchasing or overtly encouraging or discouraging play with specific toys (Fisher-Thompson, 1993; Peretti \& Sydney, 1984). Variability in these adult influences are related to adults' other beliefs, attitudes, and characteristics, several of which have been found to be associated with the degree to which individual adults encourage gender-typed toy choices (e.g., Fagot, Leinbach, \& O’Boyle, 1992). These correlated adult characteristics thus can have significant impact on a child's development, because adults' beliefs about the gender-appropriateness of toys influences both the toy purchases they make and with which toys they encourage children to play, potentially leading to children's differential development of skills, interests, and beliefs about gender roles. Little research has focused specifically on the link between adults' characteristics and their beliefs about the gender-appropriateness of certain toys.

Deaux and Kite (1987) theorized that individuals' beliefs about male and female individuals and the qualities of masculinity and femininity are linked together into a gender belief system. This system includes beliefs encompassing different dimensions of gender, including stereotypes about each gender, perceptions of violations of "traditional" gender roles, and beliefs about roles appropriate for each sex. It also includes attitudes toward gay men and lesbians, an aspect that was more emphasized by later writers (Whitley \& AEgisdóttir, 2000). Gender belief systems can be understood both as the shared norms of a given group, community, or society, as well as an area of individual variation. The current study will examine the gender belief systems on an individual level, allowing for the investigation of the predictive abilities of several aspects of the gender belief system regarding gender-typed toy ratings. 
The goal of this study was to examine the relations between adults' beliefs about the gender-appropriateness of toys and several aspects of their gender belief systems, including beliefs about homosexuality, as these beliefs have been mentioned by parents as an influence on their gender-socialization choices (Kane, 2008). This study also examined personality variables that have been found to be related to broad stereotyping; this stereotyping is not specific to gender, but may be applied to gender by the individual.

Previous research has focused on parents, but nonparent adults also often play important roles that shape children's development, including baby-sitters, day-care workers, relatives, and friends of parents. Adults have been shown to purchase more gender-typed toys for other people's children than for their own children (Fisher-Thompson, 1993), suggesting that nonparents may be especially important for children's gender-normative socialization. For this reason, and to avoid conflation of adult beliefs with the bidirectional socialization through which children are known to influence their parents (Karraker \& Coleman, 2005), the current study employed a sample of non-parent young adults. Most of these young adults (92.5\%) reported that they plan on having children in the future; therefore this sample will have the opportunity to influence the gender development of future generations of children both as non-parents, and potentially as parents.

A greater understanding of the beliefs, attitudes, and characteristics of adults who rate the gender-appropriateness of toys differently will give social scientists better insight into potential motivators or causes of beliefs about the gender-appropriateness of toys. If the links between adult characteristics and toy ratings are better understood, educational interventions that benefit children's development can be developed. Parents, teachers, and other adults who are most likely to encourage children to limit their toy play in a gender-typed way could be 
targeted, and their beliefs or misconceptions about gender-typed toys could be specifically challenged, leading to more children being encouraged to experience a diverse range of play experiences, ultimately benefiting their development.

\section{Characteristics of gender-typed toys.}

Toys that are considered by adults to be appropriate for boys, appropriate for girls, or neutral (appropriate for both) tend to have different characteristics and evoke different child play behaviors. For example, in Blakemore and Centers' (2005) study, 275 toys were first rated on a 9-point scale ranging from masculine ("Toy is only for boys") to neutral to feminine ("Toy is only for girls"). The thirty toys most representative of each category were then rated by independent raters on the degree to which they possessed several characteristics. The most feminine toys were rated as encouraging nurturance and domestic skill and focusing on physical attractiveness; toys rated as appropriate for boys were associated with excitement, danger, competiveness, and violence. Toys that were rated as neutral were associated with developing physical, artistic, cognitive, and other skills.

An earlier study (Miller, 1987) used a similar methodology, asking adult participants about both the characteristics and the gender-appropriateness of specific toys. This study found that toys that participants considered female-typed included stuffed toys and domestically oriented toys, and male-typed toys included vehicles, construction toys, guns, and balls. Female-typed toys were rated higher on dimensions of manipulability, creativity, nurturance, and attractiveness, and male-typed toys were rated as higher on symbolic play, competition, aggressiveness, constructiveness, handling, and sociability. In addition to having different characteristics, toys categorized by adults as "masculine," "feminine," and "neutral" have been shown to evoke different types of play from children. 


\section{Children's play with gender-typed toys.}

The characteristics of masculine, feminine, and neutral toys may elicit different kinds of play, which may result in differential development of children's skills. Caldera and Sciaraffa (1998) examined the differential effects of two types of dolls, one that they considered femalestereotyped (a baby doll) and one that they considered more neutral (a clown doll). They found that both toddlers and parents initiated different types of play behavior in response to the two dolls, including more nurturing and caretaking play with the baby doll and more playful interactions with the clown doll. These findings suggest that even for toys that are similar in size, shape, and type (dolls), different behavior is elicited by their correspondence to gender stereotypical roles or activities, such as caretaking.

Cherney and colleagues (2003) found that for both genders, playing with female-typed toys was associated with higher play complexity, which they defined according to the levels of symbolic and representational abilities used by the children, than playing with male-typed toys. The authors suggest that gender-typed play by children may place boys at risk by not facilitating the development that complex play achieves, as well as potentially making boys appear cognitively less developed than they actually are when assessments that include play complexity are used.

Another study (O’Brien \& Huston, 1985) found that both toddler boys and toddler girls showed higher activity levels when playing with stereotypically male toys. Leaper (2000) found that playing with a toy set he considered stereotypically feminine (toy food and dishes) elicited more collaborative play with others than a toy set he considered stereotypically masculine (toy cars and a track). If these findings generalize to other toys in gender-typed categories, children 
who play with "feminine" toys may have more opportunities to build affiliative skills than do children who play with "masculine" toys.

Several researchers have hypothesized that the different characteristics of "masculine," "feminine," and "neutral" toys, as well as the different play behavior that they evoke, may differentially impact the development of children's skills, interests, and even career choices. One specific set of cognitive skills that has been of particular interest to toy researchers is spatial skills. Tracy (1987) posited that masculine toys' greater emphasis on spatial abilities leads to the well-documented gap between boys' and girls' spatial skills, which may contribute to the overrepresentation of men in careers that use these skills, such as STEM (science, technology, engineering, and mathematics) careers.

Wai, Lubinski, and Benbow (2009) noted the key role that spatial ability plays in success in STEM careers, and Spence and Feng (2010) found that the gender gap in spatial ability can be narrowed by training emerging adult female participants on male-stereotyped video games, suggesting that exposure to cross-gender-typed recreational experiences may reduce gender differences in certain skills. Similarly, Cherney (2008) found that women's gains in mental rotation skills were significantly greater than men's after computer game practice. Individuals who are encouraged to limit their childhood play experiences to gender-typed toys might go on to pursue gender-stereotyped recreation in adolescence and adulthood, which would lead men to video games and women to other pursuits, widening the spatial ability gender gap.

In addition to the development of cognitive skills, play with exclusively gender-typed toys may also impact social development. As noted above, gender-typed toys elicit different play behaviors in children, and Moller and Serbin (1996) found that among preschool children, different styles of play result in children choosing playmates who are behaviorally compatible, 
often leading to social gender segregation. Mehta and Strough (2009) noted that gender segregation in social groups often begins due to behavioral compatibility in toy and play styles early in life and has long-lasting ramifications, many of them potentially negative, throughout the lifespan.

\section{Development of children's gender-typed toy preferences.}

Girls and boys begin to develop clear preferences for toys associated with their own gender sometime during the second year, and these preferences grow stronger through early childhood. Some researchers have claimed to find evidence of gender-typed toy preferences (in these studies, dolls for girls and vehicles for boys) among children as young as 12 months old (Jadva, Hines, \& Golombok, 2010); others find no difference between boys' and girls' toy preferences at 12 months, but do find differences emerging by 18 months (Serbin, PoulinDubois, Colburne, Sen, \& Eichstedt, 2001).

An argument is ongoing within the literature regarding which, if any, features of children's gender-typed toy preference are biological (e.g., due to prenatal androgen exposure) and which features are socially learned or constructed. Some authors argue that the emergence of differences between boys and girls in toy preferences during early childhood provides evidence that differences are learned, though these differences may also be emergent biological differences (Serbin, Poulin-Dubois, \& Eichstedt, 2001).

This learning may take place through direct adult reinforcement of play with samegender toys or through greater exposure to same-gender than other-gender toys, resulting in greater familiarity (LoBue \& DeLoache, 2011). For example, several studies have reported gender differences in children's bedroom environments, including decorations, clothes, and toys, starting from birth (Pomerleau, Bolduc, Malcuit, \& Cossette, 1990; Rheingold \& Cook, 
1975; Shakin, Shakin, \& Sternglanz, 1985). Because these choices about the objects in a child's environment are largely made by parents and other adults for very young children, adults influence children's gender-typed preferences, including toy preference, through the environment they create for a child (Pomerleau, Bolduc, Malcuit, \& Cossette, 1990). It is possible that the familiarity of these objects may lead children to a preference for or identification with them.

A toy's color is the characteristic considered most salient for children when determining whether a toy is a "boy's toy" or a "girl's toy" (Cherney \& Dempsey, 2010). No difference in the color preferences of boys and girls younger than 2 years has been found (Jadva, Hines, \& Golombok, 2010; LoBue \& DeLoache, 2011). However, LoBue and DeLoache (2011) found that most girls developed a preference for the color pink by the age of $2 \frac{1}{2}$, and most boys had developed an avoidance of it by the same age, showing that strong gender-typed color preferences have been learned by this age.

Research examining the ways that parents and other adults can influence a child's gender-typed preferences has found evidence clarifying some of the ways that their traits, beliefs, attitudes, and behaviors affect the development of gender-typed toy preferences for young children. These will be explored in the next section.

\section{Adult influences on the development of children's gender-typed toy preferences.}

Parents and other adults have been shown to exert an influence on the cognitions, beliefs, and behaviors of young children regarding the gender-appropriateness of toys. Studies have identified several ways that adults may directly influence young children's gender-typed toy preferences. For example, adults' physical presence can lead to more gender-typed toy choices by some children and exposure to adults providing counter-stereotypic models can lead 
children to make less gender-typed toy choices. Other adult behaviors and characteristics that have been shown to relate to children's gender-typed toy preferences include adults' purchases of gender-typed toys, adult behaviors that lead children to perceive that close adults think that cross-gender-typed play is "bad," parents' beliefs about the gender-appropriateness of toys, and family structure.

In a qualitative study, Kane (2006) used in-depth interviews to examine parents' responses to their preschool-aged children's gender nonconformity, including nonconformity in toy choices. One of the themes that emerged in this interview was several parents' impression that homosexuality or the appearance thereof was one of the risks of allowing or encouraging gender nonconformity in their sons. Similarly, Sandnabba and Ahlberg (1999) found that parents of 5-year-olds predicted that their children of both sexes would be homosexual as adults at a higher rate for gender-nonconforming children than for gender-conforming children. Adults' beliefs about the gender-appropriateness of toys have been found to be correlated with their status as parents or nonparents and, for parents, with their genderrelated beliefs. Less is known about the correlates of non-parents' beliefs about the genderappropriateness of toys.

\section{Experimental evidence for adult influences on children's gender-typed toy preferences.}

The mere presence of an adult observer can lead some children to choose more genderstereotyped toys than when an observer is not present. Wilansky-Traynor and Lobel (2008) classified the preschool children in their study as either gender schematic or gender aschematic; the former understand the world through gendered lenses, and the latter do not (Bem, 1981, cited in Blakemore, Berenbaum, \& Liben, 2009). Gender schematic children's toy choices were highly gender-typed whether or not an adult observer was present, but gender 
aschematic children, especially boys, played with more toys stereotypically associated with their own gender when in the presence of an observer, even choosing unattractive gendertyped toys over attractive cross-gender-typed toys.

Green, Bigler, \& Catherwood (2004) found that among a small sample of highly gendertyped preschool children, girls', but not boys', gender-typed toy play varied depending on whether the children were read gender-neutral stories or stories that introduced gender counter-stereotypic models. The girls in the sample showed more cross-gender-typed toy play after the gender counter-stereotypic models were introduced through the stories. Thus, the gender messages in the stories that adults read to children, as well as, potentially, the degree to which real-life models act in gender-stereotypical ways, may affect the toy choices and preferences of preschool children.

\section{Adult characteristics correlated with children's gender-typed toy preferences.}

Fisher-Thompson (1993) interviewed adults leaving a toy store and found that most adults had purchased toys that were gender-typed for the intended child recipient. Many gender-typed toys were reportedly purchased at the child's request. Participants were more likely to buy gender-typed toys for other children than for their own children, potentially adding evidence to Campenni (1999)'s idea that interaction with one's own child leads to greater tolerance for gender-neutral toys for that child. More gender-typed than neutral toys were purchased for children over the age of 3; the opposite was true for children under 3. Fewer than $3 \%$ of adults purchased cross-gender-typed toys. The author concluded that gender-typed play is encouraged through purchase of gender-typed toys by adults, including adults who are not a given child's parents. 
Preschool children who report perceiving that one or more familiar person in their lives would think cross-gender-typed play is "bad" have been shown to play with cross-gender-typed toys less than children without such perceptions. This finding held true independently of the children's levels of gender-stereotype awareness (Raag, 1999). Another similar study by the same author found that the way a toy is presented to a child affects the child's response to it. Boys in the study showed more stereotyped choices when the toys were presented with gender-typed toy labels than when they were presented neutrally (Raag \& Rackliff, 1998).

A more recent study (Freeman, 2007) also found that young children, particularly boys, predicted that their parents would react negatively to cross-gender-typed toy choices; however, most of the parents in the sample reported that they would be accepting of such choices. The author hypothesized that, despite their reported beliefs, parents may be sending mixed messages to their children in other ways about which traits and behaviors are acceptable for each gender.

In a study by Peretti and Sydney (1984), parents' reported toy choice preferences were found to be significantly related to their children's observed toy preferences; parents with more gender-typed toy choice preferences for their children had children who showed more gendertyped toy choice in preschool play situations. Additionally, parents with more gender-typed toy choice preferences reported more conscious socialization of their children into gender-typed roles. Many of these parents reported developing toy choice preferences for their children even before the children were born, based on the interests and characteristics that they assumed their children would have based on sex alone.

One example of how family structure is related to children's toy preferences was described by Hupp, Smith, Coleman and Brunell (2010). They found that children whose 
mothers were unmarried showed less gender-typed knowledge, including knowledge of which toys are stereotypically associated with each sex, than did children with married mothers. The researchers found evidence that this difference was due to unmarried mothers engaging in more androgynous behavior.

\section{Correlates of adults' beliefs about the gender-appropriateness of toys.}

A study by Wood, Desmarais, and Gugula (2002) used toy play situations in which each child interacted with his or her own parent, the parent of another child, and an adult who was not a parent to determine whether parental status relates to encouragement of gender-typed toy selection. Parents interacting with their own children rated toys as more desirable in general than did the other two categories of adults, but there were not significant differences among the categories of adults regarding the amount of time spent playing with gender-typed and cross-gender-typed toys, nor were there significant differences in the adults' ratings of the gender-appropriateness of the toys.

In contrast to this finding, Campenni (1999) found that parents rated more toys as neutral than did nonparents. The author suggested that parents' exposure to their own children's play leads to more neutral ratings, perhaps because they have become more flexible in response to their own children's interests and play patterns, some of which may be crossgender-typed. She also found that ratings of the gender-appropriateness of toys among parents are influenced by whether they have children of only one or both sexes. Among mothers, having only daughters was associated with more neutral toy ratings than other mothers; among fathers, having children of both sexes was associated with more neutral ratings compared to other fathers. 
Fagot, Leinbach, and O’Boyle (1992) found that mothers with more stereotypical beliefs about women and gender roles within the family engaged in more gender-stereotyped play with their children. These children showed more gender stereotype knowledge than did the children of mothers with less stereotypical beliefs. Similarly, Weinraub (1984) found that fathers who scored higher on a femininity scale had sons with less gender-typed toy preferences.

Although several characteristics of adults, including marital and parental status, beliefs, and attitudes, have been shown to influence children's development through the toys with which they encourage children to play, it was important to more fully understand which adult characteristics are directly linked to the encouragement of gender-typed toy play. It was hypothesized that participants' gender belief systems, as measured by several different genderrelated beliefs and attitudes variables as well as beliefs and attitudes about homosexuality, would predict participants' ratings of the gender-appropriateness of toys. Personality variables that are related to broader stereotyping were also included, because gender-stereotyping may be a specific instance of a general tendency for participants to stereotype.

Some other adult characteristics that have not been previously or fully examined as correlates of toy gender-typing but were explored in this study include beliefs and attitudes regarding gender, homonegativity, beliefs about the etiology of homosexuality, social dominance orientation, and lay theories of personality.

\section{Adult characteristics hypothesized to be related to toy gender-appropriateness} ratings.

Beliefs, attitudes, and characteristics regarding gender. 
As previously discussed, dimensions of adults' gender belief systems, including their beliefs, attitudes, and characteristics regarding gender, have been linked to both their own gender-typed toy preferences and those they encourage or discourage in children. More "traditional" or stereotyped beliefs and characteristics have been shown to correlate with stronger gender-typing of toys (Fagot, Leinbach, and O'Boyle, 1992; Peretti and Sydney, 1984). The present study sought to extend this line of inquiry and learn if these correlations also exist among nonparent adults, examining three dimensions of the gender belief system: ambivalent sexism, instrumental/expressive traits, and neosexism. Examining multiple dimensions of attitudes regarding gender further clarified the relationship between gender attitudes and gender-typing of toys to a degree that studies using monodimensional measures have not. Ambivalent sexism theory (Glick \& Fiske, 1997) distinguishes between two forms of sexism, benevolent and hostile sexism. Benevolent sexism (BS) includes subjectively positive feelings toward women but idealizes them and places them in traditional roles (Glick et al., 2000). Hostile sexism (HS) includes subjectively negative feelings toward women and degrades them (Glick et al., 2000). Both of these types of sexism are measured by the Ambivalent Sexism Inventory (ASI). Overall ambivalent sexism scores, as well as scores for each subscale, are individual difference variables that have been linked to other characteristics, including conservative ideology and motivation for social change.

Blakemore and Hill (2008) found that for parents of both girls and boys, strong endorsement of gender-typed toys for their children was significantly correlated with high overall scores on the ASI, indicating a high degree of ambivalent sexism. Christopher and Mull (2006) found correlations between ambivalent sexism and several facets of conservative ideology, including a link between hostile sexism and social dominance, another individual 
difference variable that was included in this study. Becker and Wright (2011) found that exposure to benevolent sexism decreased women's motivation for social change, but exposure to hostile sexism increased it. Because individuals who are concerned with social change may be more supportive of nontraditional attitudes toward gender, the two subscales of the ASI were hypothesized to relate differently to toy ratings in the current study.

Traits corresponding to the stereotypical male gender role have often been described as instrumental traits; traits corresponding to the stereotypical female gender role have been described as expressive traits (Spence, 1980). Individuals vary widely on the degree to which they report possessing each of these sets of traits. Since the development of scales measuring instrumentality and expressiveness several decades ago (Bem, 1981; Spence, Helmreich, \& Stapp, 1974), a trend has emerged. The gender gap in expressiveness, with female individuals reporting more expressive traits, has remained, but the gender gap in instrumentality, in which male individuals report more instrumental traits, has begun to narrow, with male and female individuals recently reporting similar levels of instrumentality (Spence \& Buckner, 2000). This study's inclusion of measures of expressive and instrumental traits was warranted by previous studies that have found positive correlations between adults' gender-typed traits and the degree to which their toy choices for children are gender-typed (Weinraub, 1984).

Neosexism is a type of gender prejudice that is not overtly hostile to women but that includes lack of awareness of discrimination against women, which may lead to lack of support for gender equality efforts (Tougas, Brown, Beaton, \& Joly, 1995). Neosexism has been found to be positively correlated with more "traditional" gender-role attitudes and has been shown to partially mediate the link between gender role beliefs and gender awareness (Martinez et al., 2010). Neosexism was relevant to this study because those who are unaware of discrimination 
against women may be less likely to support efforts toward egalitarianism, including providing equal opportunities for children to play with a range of toys.

\section{Homonegativity and beliefs about the etiology of homosexuality.}

One motivation for gender-typing children's toys may be fear that cross-gender-typed toy play could cause a child to become homosexual. Therefore the current study measured participants' attitudes toward homosexual individuals and beliefs about the etiology of homosexuality. Kite and Deaux (1987) found evidence for the implicit inversion theory of homosexuality, which suggests that individuals perceive homosexual individuals as having characteristics similar to, if not indistinguishable from, those of heterosexual members of the other sex.

Relatedly, Schope and Eliason (2004) found that negative attitudes and behaviors toward homosexual individuals are partially elicited by the perception that homosexual individuals' behavior is only appropriate for the other sex. Whitley (2001) found that individuals who have negative attitudes toward cross-gendered behavior also have negative attitudes toward homosexual individuals. These findings suggest that disapproval of cross-gendered behavior and characteristics is an important element of homonegativity (negative attitudes toward homosexual individuals).

Individuals who believe that the etiology of homosexuality is primarily environmental rather than biological are more likely to report prejudice against homosexuals and less likely to support gay-relevant legislation (Smith, Zanotti, Axelton, \& Saucier, 2011). The perception that a child playing with cross-gender-typed toys is behaving in a way only appropriate for the other sex may elicit negative responses from individuals with homonegative attitudes or who believe that the etiology of homosexuality is primarily environmental (and therefore that cross-gender- 
typed play could cause homosexuality). The current study measured homonegativity and beliefs about the etiology of homosexuality in order to test this possibility.

Both old-fashioned and modern heterosexism, defined respectively as overt prejudice toward homosexuality and subtler hostility toward the collective identity and political demands of homosexuals, have been hypothesized to be created by social systemic beliefs (Eldridge \& Johnson, 2011). Higher scores on scales measuring both of these types of heterosexism are predicted by having a high social dominance orientation score. Therefore, as well as homonegativity and beliefs about the etiology of homosexuality, the current study measured social dominance orientation.

\section{Social dominance orientation.}

Social dominance orientation (SDO) is a personality variable that refers to support for one's in-group dominating over out-groups and is highly linked to authoritarianism (Eldridge \& Johnson, 2011; Pratto, Sidanius, Stallworth, \& Malle, 1994). SDO is predictive of endorsement of traditional gender roles (Peterson \& Zurbriggen, 2010) and parenting styles that emphasize conformity and tradition (Knafo, 2003), both of which could be motivations for encouraging gender-typed toy choices for children.

\section{Lay theories of personality.}

Dweck and colleagues (Dweck, Chiu, \& Hong, 1995; Chiu, Hong, \& Dweck, 1997) discussed the role of implicit theories in individuals' social judgments and motivation. They postulated two types of lay theories of personality: entity theorists believe that personal attributes are fixed, and incremental theorists tend to perceive personal attributes as more malleable. As a result of these implicit theories, individuals who are classified according to this model as entity theorists tend to make strong global inferences based on another person's 
current behavior, including inferences about his or her traits and predictions about future behaviors (Chiu, Hong, \& Dweck, 1997).

This model has been applied to domains including academic achievement, learned helplessness, and stereotype formation. Levy, Stroessner, and Dweck (1998) found that entity theorists are more likely than incremental theorists to agree that stereotypes about groups are true and to make judgments about individuals quickly based on perceptions about group traits. This model had not yet been applied to stereotypes about the gender-appropriateness of toys, and was included in the current study. Because the literature does not support a directional hypothesis, the relation between implicit theories and toy ratings was examined in an exploratory manner.

\section{Sex of rater and gender type of toy.}

One result of changing gender norms is that there are stronger social sanctions for male individuals acting in a feminine way than for female individuals acting in a masculine way. This pattern has been shown to apply to the toy choices considered acceptable for children; boys receive more criticism from adults and peers than girls do for cross-gender-typed toy play (Freeman, 2007). Similarly, fathers have been shown to rate toys in a more gender-typed way than do mothers (Burge, 1981). The current study included analyses to determine whether these patterns were true of our sample.

\section{Statement of the Problem}

The Bent Twig Theory posits that small biological differences early in life can become exacerbated by differential environmental responses. One specific application of this theory to gender development suggests that exposure to exclusively or primarily gender-typed toys could exacerbate small early differences between male and female children, including activity level, 
affiliative behavior, interests, playmates, and spatial skills. Toys play a major role in children's social and cognitive development, and development is differentially impacted by play with different types of toys (Blakemore \& Centers, 2005). Starting at a young age, many children can identify and, eventually, tend to prefer the toys stereotypically associated with their gender (Serbin et al., 2001). If a child is exposed to or encouraged to play exclusively or primarily with gender-typed toys, there may be consequences, including limited or enhanced cognitive (Tracy, 1987) and physical (Blakemore \& Centers, 2005) development, increased gender segregation in social groups (Moller \& Serbin, 1996), and differential development of skills that may lead to stereotyped career choices (Wai et al., 2009).

Parents and other adults have been shown to play an important role in children's identification of and preference for gender-typed toys (Peretti \& Sydney, 1984). Adults' characteristics, including beliefs about the gender-appropriateness of toys, gender beliefs and characteristics, and family structure, have been shown to be associated with children's gendertyped toy preferences. Adult characteristics that are associated with their beliefs about the gender-appropriateness of toys include their status as parents or nonparents and, for parents, their gender-related beliefs. Because of the influence of adults on children's gender-typed toy preferences, it is important to understand how adults' own beliefs are related to their endorsement of toy choices that are more stereotyped or more neutral.

The current study asked nonparent adults about their beliefs regarding the genderappropriateness of a range of specific toys. It also asked them about several components of their gender belief systems, including beliefs and attitudes related to homosexuality and personality variables related to stereotyping that were hypothesized to be related to their toy ratings. Although this method did not determine the cause of adults' gender-typed perceptions 
and choices of toys, it did contribute to a greater understanding of which adults may encourage gender-stereotyped toy choices and which may encourage a range of toy choices in children.

Several adult characteristics were studied. Components of the gender belief system were measured, as parents with sexist attitudes and more "traditional" gender role orientations tend to have children with greater awareness of gender differences and more gender-typed toy preferences (Weinraub, 1984). Beliefs about the etiology of homosexuality and attitudes toward homosexuality were measured, because parents report concern about homosexuality as a major factor in their decisions about gender socialization (Kane, 2006) and previous studies (Schope \& Eliason, 2004) have shown that individuals with homonegative attitudes have low tolerance for behaviors that they consider to be cross-gendered.

As gender-typing of toys is one domain-specific instance of stereotyping, personality variables related to stereotyping were measured, assessing the construct of social dominance orientation, as those who score highly on these measures tend to show more sexism and homonegativity in general (Eldridge \& Johnson, 2011). An additional exploratory research question, without a directional hypothesis, was whether lay theories of personality, which describe how fixed individuals believe traits to be, were related to toy ratings.

Finally, potential differences between the magnitude of gender-typing for toys that are strongly associated with each gender were explored, as well as the effect of the sex of the rater. Evidence suggests that it is more acceptable for girls to play with "masculine" toys than for boys to play with "feminine" toys, and that fathers tend to gender-type toys more strongly than mothers. Both the sex of the rater and the type of toys were examined for these patterns.

\section{Research Questions and Hypotheses}


The current study investigated characteristics that were potentially correlated with adults' ratings of the gender appropriateness of toys. Four research questions were tested.

Research question 1: Attitudes and beliefs regarding homosexuality will be related to gender-typing of toys.

Hypothesis 1: More highly homonegative attitudes will be associated with more gender-typing of toys.

Rationale: Because homonegative attitudes are associated with disapproval of crossgender-typed behavior (Schope \& Eliason, 2004), individuals with highly homonegative attitudes may be more likely to disapprove of children playing with toys that are considered cross-gender-typed.

Hypothesis 2: Stronger beliefs that the etiology of homosexuality is due to nurture will be associated with more gender-typing of toys.

Rationale: Individuals who believe that homosexuality is primarily due to nurture may believe that cross-gender-typed toy play is one of the experiences that could lead an individual to become homosexual and therefore may be more likely to endorse gender-typing of toys.

Research question 2: Attitudes and beliefs related to gender roles will be related to gender-typing of toys.

Hypothesis 3: Higher ambivalent sexism scores will be associated with more gendertyping of toys.

Rationale: Individuals who have sexist beliefs about men's and women's traits and roles are more likely to hold traditional attitudes about the gender-appropriateness of toys.

Hypothesis 4: Greater instrumentality in men and greater expressiveness in women will be associated with more gender-typing of toys. 
Rationale: Gender-typed traits in parents have been shown to be predictive of their children's gender-typed toy preferences. This hypothesis will examine whether adults' attitudes about toys are a potential mechanism underlying the relation between adults' gender-typed traits and their children's gender-typed toy preferences.

Hypothesis 5: More neosexism will be associated with more gender-typing of toys.

Rationale: Participants who are high in neosexism are less aware of gender inequality, and therefore are less likely to make efforts toward equality, including challenging gendertyping of toys.

Research question 3: Personality variables related to general stereotyping will be associated with more gender-typing of toys.

Hypothesis 6: Higher social dominance orientation will be associated with more gender-typing of toys.

Rationale: Those with high social dominance orientation feel the need to maintain the power balance in society, which may include maintaining the status quo through gender-typing of toys.

Research question 4: The degree to which toys are gender-typed will vary by the category of each toy and the sex of the participant.

Hypothesis 7: The toys rated as the most feminine will be more gender-typed than toys rated as the most masculine.

Rationale: There are stronger social sanctions against male children playing with feminine toys, so participants will be less likely to say that both sexes can play with feminine toys than masculine toys. 


\section{Hypothesis 8: Male participants will gender-type toys more than will female}

participants.

Rationale: Fathers have been shown to gender-type more than mothers; it is predicted that this gender difference will apply to nonparents as well.

\section{Method}

Participants were college students from a large mid-Atlantic university. They were recruited from psychology classes and received class credit or extra credit for participation. Participants who already had children were excluded from analyses so that the study examined nonparents only. Power calculations using G*Power (Buchner, Erdfelder, \& Faul, 1997) estimated that for a correlation probability of 0.30 and 0 for the alternate and null hypotheses, respectively, and power of .90 at the .01 level, 158 participants were needed in each group (i.e., 158 male participants and 158 female participants), for a total of 316 participants. All data were collected between late August and late September 2012. Data were collected from 565 students, 277 male and 262 female; during initial recruitment, which lasted about two weeks, only about $20 \%$ of participants were male, so after collecting 262 female cases, the description of the study was changed, requesting only male participants. After the elimination of students who were parents $(\mathrm{N}=6)$, who withdrew from the study early $(\mathrm{N}=18)$, and who failed embedded validity checks ( $N=121), 202$ male and 215 female students remained.

All measures were collected online through the university's survey system. The title of the survey was "Ratings of Toys and Attitudes/Beliefs." After participants agreed with an informed consent statement, they completed a series of questionnaires. Measures included a demographic questionnaire, a toy rating task, the Modern Homonegativity Scale, the Homosexuality Beliefs Questionnaire, the Ambivalent Sexism Inventory, the Personal Attributes 
Questionnaire, the Neosexism Scale, the Social Dominance Orientation scale, and the implicit theories measure. The internal reliabilities reported below were assessed using coefficient alpha.

\section{Measures}

Demographic questionnaire. Participants were asked to complete a demographics questionnaire (see Appendix A) that asked about their age, sex, year in college, race, sexual orientation, marital and parental status, and whether they plan on having children. The questionnaire also asked about political beliefs, degree of religiosity, how frequently they have contact with infants and children, how much they like infants and children, their family constellations (age and gender of their siblings), and the highest level of education achieved by each of their parents.

Toy rating task. This task (see Appendix B) measured the degree to which participants rate toys in a gender-typed way. Participants were presented with a list of toys and asked to use a 9-point Likert-type scale to indicate for which children they consider each toy appropriate, with 1 labeled, "Only appropriate for girls," and 9 labeled, "Only appropriate for boys." Point 3 was labeled "Somewhat more appropriate for boys than girls," with 7 labeled, "Somewhat more appropriate for girls than boys." Point 5 was labeled "Equally appropriate for boys and girls." This rating scheme was adapted from Campenni (1999). A single Likert-type scale was chosen to measure participants' beliefs about the gender-appropriateness of toys because this has been the format most often used in the literature when adults are asked about their beliefs about toys (e.g., Blakemore \& Centers, 2005; Campenni, 1999; Cherney, 2005; Cherney et al., 2003), although other methods also have been used (e.g., Wood, Desmarais, \& Gugula, 2002). 
To reduce the influence of other toy characteristics such as age-appropriateness, the current study used toys selected from the United States Consumer Product Safety Commission's list of toys appropriate for 2-year-olds (Smith, 2002). An equal number of feminine, masculine, and neutral toys were included, as determined by an earlier pilot study. In order to calculate a toy gender-typing score for each participant, all responses were first recoded to range from 1 to 5 (i.e., 6 recoded to 4, 7 recoded to 3, etc.), with lower scores reflecting more gender-typing regardless of which gender was chosen, and higher scores indicating more gender-neutral ratings (Campenni, 1999; Fisher-Thompson, 1990). Scores were then reverse-coded $(1=5,2=4$, etc. $)$ so that higher gender-typing scores indicated more gendertyping, for ease of interpretation. A composite toy-rating score was calculated for each toy by averaging all of the recoded and reverse-coded scores across participants for that toy. A composite toy-rating score was calculated for each participant by averaging all of that participant's recoded and reverse-coded toy ratings.

Previous studies in our lab and other labs have found that individuals almost never rate toys in a cross-gender-typed way, varying instead from gender-typed to neutral in their ratings. For example, Wood and colleagues (2002) found that $0 \%$ of adults categorized any stereotypically masculine toys as feminine, and $2.7 \%$ of adults categorized any stereotypically feminine toys as masculine. Therefore, the degree of gender-typing measured by this composite score was assumed to lack statistical interference from individuals rating toys in a cross-gender-typed way. For the gender-typed toys in this sample, the rate of cross-gendertyped ratings was very low: baby doll (0\%), large truck (1.2\%), train (1.2\%), dress-up clothes (0.2\%), dress-me doll (0.5\%), and toy lawnmower (1.2\%). For this study, the internal consistency 
for the toy scale was .79. Descriptive statistics for individual toy ratings (after recoding) by gender can be found in Table 1.

Modern homonegativity scale (MHS). The MHS (Morrison \& Morrison, 2002; see Appendix C) consists of two 12-item scales that measure attitudes toward gay men and lesbian women, respectively. Higher scores indicate more homonegative attitudes. A sample item is, "The media devote far too much attention to the topic of homosexuality." Participants rated their agreement with each statement on a 5-item Likert-type scale ranging from "Strongly disagree" to "Strongly agree." After reverse coding items that were phrased in the opposite direction, responses were averaged to form a composite score for each scale. These scales have demonstrated acceptable internal consistency, with a Cronbach's alpha of .93 for the combined scale (Rye \& Meaney, 2010). For this sample, the MHS had an internal consistency of .93 for both the gay men and the lesbian subscales. One of the items refers to Canadians; in the present study, "Americans" was substituted to reflect the sample being studied.

Homosexuality beliefs questionnaire-short form (HBQ-S). The homosexuality beliefs questionnaire (Smith, Zanotti, Axelton, \& Saucier, 2011) asks about the participant's beliefs about the etiology of homosexuality. It consists of two subscales, nature (10 items; sample item: "People are born homosexual.") and nurture (13 items; sample item: "Homosexuality is a result of peer pressure."). The authors of the scale found that both subscales demonstrated a high level of internal consistency; the alphas were .91 and .87 for the nurture and nature subscales, respectively. In the current sample, the alphas were .96 and .91 .

Ambivalent sexism inventory (ASI). This measure, developed by Glick and Fiske (1997; see Appendix E), consists of 22 items that ask how much the participant agrees with statements about men's and women's relationships and roles on a scale from 0 ("Disagree strongly") to 5 
("Agree strongly"). It provides an overall sexism score, as well as scores for two subscales, Hostile Sexism (sample item: "Women seek to gain power by getting control over men") and Benevolent Sexism (sample item: "A good woman should be set on a pedestal by her man"). Both the overall scale and the subscales have shown internal consistencies within an acceptable range, with alphas between .8 and .9, in Glick and Fiske's 1996 set of studies. For this sample, the alphas were .86 and .76 for hostile and benevolent sexism, respectively.

Personal attributes questionnaire (PAQ). The PAQ (Spence, Helmreich, \& Stapp, 1974; see Appendix F) asks participants to rate themselves on 24 trait descriptions on a 5-point bipolar numerical scale with an opposing trait on each pole. Eight items form the masculine/instrumental subscale (sample item: "Very competitive/Not at all competitive"), and eight items form the feminine/expressive subscale (sample item: "Very gentle/Very rough"). The eight items that measure androgyny are rarely used, and were not included in this study. In previous studies, the coefficient alpha for the instrumental subscale was .85 (Spence et al., 1974), and the alpha for the expressive scale was .82 (Spence et al., 1974). In the current sample, the alphas were .51 and .79 for the instrumental and expressive scales, respectively. The low reliability of the instrumental subscale was largely because of a single item, "Can make decisions easily/Has difficulty making decisions;" removing this item resulted in an internal consistency of .70. The modified subscale was used for the remainder of the study. Higher scores indicate higher endorsement of instrumental and expressive traits. Participants' scores for each subscale were calculated by averaging the ratings of the eight items in that subscale.

Neosexism scale. This scale (see Appendix G) was developed to measure the modern forms that sexism often takes (Tougas, Brown, Beaton \& Joly, 1995). It consists of 11 items (sample item: "It is difficult to work for a female boss"). Participants rated their endorsement of 
each item on a 7-point scale, with 1 indicating total agreement and 7 indicating total

disagreement. Composite scores were calculated by averaging each participant's responses. The authors found an internal consistency of .81 and a test-retest reliability of .84. For the current sample, the internal consistency was .83. One of the items refers to Canada; in the present study, "USA" was substituted to reflect the sample being studied.

Social dominance orientation scale (SDO). The 14-item version of the SDO (Pratto et al., 1994; see Appendix H), which measures desire for in-group dominance and belief in out-group inferiority, was used in the present study. The scale asks, "Which of the following objects or statements do you have a positive or negative feeling toward?" with a response scale from 1 ("very negative") to 7 ("very positive"). A sample item is, "To get ahead in life, it is sometimes necessary to step on other groups." After reverse-coding items that are phrased in the opposite direction, an average score was calculated for each participant. Researchers found a Cronbach's alpha of .88 for the 14-item scale. In this study, the alpha was .94.

Measure of implicit theory. The domain-general measure of implicit personality theory used by Dweck and colleagues (e.g., Dweck et al., 1995) consists of just three items (see Appendix I), all phrased as entity theory statements. A sample item is "Everyone is a certain kind of person and there is not much that can be done to really change that." Items are rated on a 6-point Likert-type scale from 1 ("Very strongly disagree") to 6 ("Very strongly agree"). Previous studies using this measure have found high internal consistency, with alphas between .73 and .96, with a 2-week test-retest reliability of .82 (Chiu et al., 1997). For this sample, the internal consistency was .84 . Scores were calculated by averaging the three responses. Dweck and colleagues (Dweck et al., 1995) have classified participants with mean scores of 3.0 or below as entity theorists, and participants with mean scores of 4.0 or above were classified as 
incremental theorists (), excluding participants with scores between 3.0 and 4.0 (typically about $15 \%$, according to previous studies), from the analyses. However, the scores were used a continuous variable in the present study.

Big five personality inventory. This 44-item self-report personality inventory (Appendix J) captures five major personality traits: extraversion, agreeableness, conscientiousness, neuroticism, and openness to experience (John, Donahue, \& Kentle, 1991). The phrase "I see myself as someone who..." is completed by 44 characteristics. For each characteristic, participants rate themselves on a scale from 1 (Disagree Strongly) to 5 (Agree Strongly). Sample items include "is talkative [extraversion]," "can be moody [neuroticism]," and "does a thorough job [conscientiousness]." Responses are averaged for each subscale. In this sample, the internal consistencies were $.86(\mathrm{E}), .75(\mathrm{~A}), .77(\mathrm{C}), .82(\mathrm{~N})$, and $.77(\mathrm{O})$.

Crowne-Marlowe social desirability scale. The classic 33-item CMSD Scale (Crowne \& Marlowe, 1960; Appendix K), consists of 33 true-false items and assesses response bias, specifically the degree to which participants are providing answers that are likely to be looked upon favorably by others. A sample item is "I never resent being asked to return a favor." In this sample, the internal consistency was .77.

Validity checks. Two validity checks were included in the study to detect random, nonvalid responding. These questions were embedded within questionnaires and gave specific instructions for responding. For example, between items 14 and 15 of the $\mathrm{BFI}$, an item appeared that stated, "Please answer 'Agree a little' for this question." The second validity check was located in the gay men subscale of the MHS. Participants who failed both of these validity checks, choosing responses other than the one in the instructions, were excluded from 
analyses. Many of the excluded participants provided the same response down entire pages of the study, despite reverse-coded items.

Order of measures. Every participant received the measures in the same order. The first measure was the toy rating task, to avoid participants being primed by later questionnaires about gender and sexuality. The Big Five Inventory was next, followed by the Ambivalent Sexism Inventory, the gay men subscale of the Modern Homonegativity Scale, the Homosexuality Beliefs Questionnaire, the lesbian subscale of the MHS, the Personal Attributes Questionnaire, the Neosexism Scale, the Social Dominance Orientation Scale, the measure of implicit theory, and the Crowne-Marlowe Social Desirability Scale. The demographic questionnaire was presented last, because it was thought to be the least cognitively taxing and to avoid priming other responses by making demographic characteristics such as gender and sexual orientation salient.

\section{Analyses}

\section{Sample characteristics.}

Demographic characteristics of the study sample divided by sex are presented in Table 2. The only statistically significant differences between male and female participants were that male participants reported less frequent contact with both infants and children and reported liking both infants and children less than female participants did. The male and female participants did not differ on the other demographic characteristics.

Participants who indicated that the plan on having children reported significantly more contact with infants $(t(415)=-3.44, p=.001)$ and children $(t(407)=-3.87, p<.001)$, more liking of infants $(t(413)=-6.90, p<.001)$ and children $(t(412)=-7.67, p<.001)$, more religiousness $(t(411)=3.99, \mathrm{p}<.001)$, and more benevolent sexism $(t(415)=3.65, \mathrm{p}<.001)$ than participants 
who reported not planning on having children. Due to these differences, proposed hypotheses were tested both including and excluding participants who are not prospective parents. The prospective parent sample consisted of 179 male participants and 189 female participants.

\section{Preliminary analyses.}

Before testing hypotheses, preliminary analyses of the data were conducted. These analyses included checking for missing data; after eliminating participants who failed validity checks, missingness was very low (an average of 1.62 missing scores per variable, out of 420 participants, with no one variable exceeding 6 missing scores). Mean imputation was used, replacing each missing value with that participants' mean item score for that scale for participants who answered at least $80 \%$ of the questions for each scale, which accounted for all of the missing data.

Additionally, assumptions underlying the use of correlation and regression, including normality, were tested. Three scale score variables, PAQ-F, HBQ-nurture, and SDO, were transformed to improve their normality. PAQ-F was moderately negatively skewed and a reflect and square root transformation was used. HBQ-nurture was substantially positively skewed and a logarithmic transformation was used. SDO was moderately positively skewed and a square root transformation was used (Tabachnick \& Fidell, 2013).

The presence of univariate outliers was assessed by checking for scale scores that were more than 3.29 standard deviations from the mean (Tabachnick \& Fidell, 2013). No such outliers were detected. Multivariate outliers were assessed by comparing participants' Mahalanobis distances to the critical value for nine dependent variables, 27.88. No participants exceeded this critical value. 
$t$-tests were used to compare the scores of male and female participants on each of the measures (see Table 3). Male participants had significantly more gender-typed toy ratings, reported more hostile sexism and homonegativity toward both gay men and lesbians, had stronger beliefs that the etiology of homosexuality is nurture, reported more masculine/instrumental and fewer feminine/expressive traits, reported more neosexism and more social dominance orientation, and had lay theories of personality closer to entity theorists.

Correlation matrices including all scale scores across gender and by gender (see Tables 4-6) were assessed before the hypotheses were tested to avoid multicollinearity. Initially, the lesbians and gay men subscales of the Modern Homonegativity Scale were treated separately. However, these subscales were strongly correlated in this sample, at $r=.93$ across participant gender. Multicollinearity diagnostics resulted in unacceptable Tolerance $(.13$, which is below the cut-off of .20) and Variance Inflation Favor (7.61, which is above the cut-off of 4.0) values (Howell, 2010). Therefore, these two scales were averaged together (which was possible due to their identical scaling) into a single MHS variable.

The two subscales of the Ambivalent Sexism Inventory, hostile sexism and benevolent sexism, were only correlated at $r=.28$ across participant gender, and when they were treated as a single scale, the internal consistency was unacceptably low $(\alpha=0.32)$. Therefore, these subscales were treated separately in subsequent analyses. After determining that correlations between scale scores did not differ in direction or significance between genders, analyses were covaried by participant gender to avoid illusory correlations based on gender differences.

A visual inspection of bivariate scatterplots revealed no linearity problems, so there were not curvilinear relations between variables. All hypotheses were tested at a significance 
level of .001, to correct for the potentially inflated risk of committing a Type I error due to multiple comparisons (Howell, 2010). Analyzes that controlled for a socially desirable response pattern, measured by the Crown-Marlowe Social Desirability Scale (Crowne \& Marlowe, 1960), found very minor differences compared to the uncontrolled analyses. Only one finding changed significance (see Table 7), therefore social desirability was not controlled for in the main analyses.

\section{Analyses}

Hypothesis 1 predicted that more highly homonegative attitudes would be associated with more gender-typing of toys; it was tested by calculating a partial Pearson's productmoment correlation coefficient using the toy gender-typing scores and the combined Modern Homonegativity Scale score, controlling for participant sex. This hypothesis was supported for both samples. For the full sample, $r(413)=.40, p<.001$, and the prospective parent sample, $r(379)=.40, p<.001$, with participants, reporting more gender-typed toy ratings when they reported more homonegativity.

Hypothesis 2 predicted that stronger beliefs that the etiology of homosexuality is due to nurture would be associated with more gender-typing of toys. This hypothesis was tested by calculating a partial Pearson's product-moment correlation coefficient using the toy gendertyping scores and the transformed nurture subscale scores of the Homosexuality Beliefs Questionnaire, controlling for participant sex. This hypothesis was supported for both samples. For the full sample, $r(413)=.25, p<.001$, and the prospective parent sample, $r(379)=.24, p<$ .001 , participants rated toys in a more gender-typed way when they reported stronger beliefs that the etiology of homosexuality is nurture. 
Hypothesis 3 predicted that higher ambivalent sexism scores would be associated with more gender-typing of toys. As previously mentioned, the correlations between ASI-HS and ASIBS were not strong enough to justify combining these variables into a single scale, and therefore this hypothesis was also tested with each subscale separately. A partial Pearson's product-moment correlation coefficient was calculated using the toy gender-typing scores and the hostile sexism subscale and transformed benevolent sexism subscale of the ASI, controlling for participant sex. This hypothesis was supported for both samples. For the full sample, both hostile sexism, $r(413)=.29, p<.001$, and benevolent sexism, $r(413)=.34, p<.001$, were significantly related; the same was true for the prospective parent sample for both hostile $\operatorname{sexism}(r(379)=.33, p<.001)$ and benevolent sexism $(r(379)=.33, p<.001)$. Overall, there was a positive relation between rating toys in a more gender-typed way and higher levels of ambivalent sexism.

Hypothesis 4 predicted that greater instrumentality in men and greater expressiveness in women would be associated with more gender-typing of toys. This hypothesis was tested by calculating a partial Pearson's product-moment correlation coefficient using the toy gendertyping scores and the modified instrumental subscale and transformed expressive subscale of the PAQ, controlling for participant sex. This hypothesis was not supported for either sample. For the full sample, neither the instrumental subscale, $r(413)=.09, p=.056)$, nor the expressive subscale, $r(413)=.10, p=.035$, were significantly correlated with gender-typed toy ratings; the same was true of the instrumental subscale, $r(379)=.086, p=.094$, and the expressive subscale, $r(379)=.12, p=.016$, of the prospective parent sample.

Hypothesis 5 predicted that more neosexism would be associated with more gendertyping of toys. A partial Pearson's product-moment correlation coefficient was calculated using 
the toy gender-typing scores and the Neosexism Scale scores, controlling for participant sex.

This hypothesis was supported for both samples. For the full sample, $r(414)=.30, p<.001$, and the prospective parent sample, $r(380)=.29, p<.001$, individuals who rated toys in a more gender-typed way also reporting more neosexism.

Hypothesis 6 predicted that higher social dominance orientation would be associated with more gender-typing of toys. This hypothesis was tested by calculating a partial Pearson's product-moment correlation coefficient using the toy gender-typing scores and the transformed social dominance orientation scale scores, controlling for participant sex. This hypothesis was supported for both samples. For the full sample, $r(413)=.22, p<.001$, and the prospective parent sample, $r(379)=.23, p<.001$, with participants who rated toys in a more gender-typed way also reporting higher social dominance orientation.

The partial correlations for Hypotheses 1-6 were also calculated separately for maletyped, female-typed, and neutral scores. The pattern of significant correlations was identical for male-typed and female typed toys; none of the correlations between scale scores and neutral toys were significant (see Tables 8 and 9).

Hypothesis 7 predicted that the toys rated as the most feminine would be more gendertyped than toys rated as the most masculine. A repeated-measure $2 \times 3$ ANOVA was used to determine whether the mean toy composite scores for the male-typed, female-typed, and neutral toys were significantly different and to examine the effect of participant sex (Hypothesis 8). Covariates included participant age, year in college, sexual orientation, religiousness, and political beliefs. Mauchly's Test of Sphericity showed that the assumption of sphericity was not violated. 
This hypothesis was supported for both samples. For the full sample, there was a significant effect for type of toy, Wilks' Lambda $=.95, F(2,393)=10.44, p<.001$, multivariate partial eta squared $=.05$. Pairwise comparisons revealed that each of the three toy types differed significantly from each of the others. For the prospective parent sample, there was a significant effect for type of toy, Wilks' Lambda $=.96, F(2,360)=6.64, p=.001$, multivariate partial eta squared $=.036$. Pairwise comparisons once again revealed that each of the three toy types differed significantly from each of the others.

Hypothesis 8 predicted that male participants would gender-type toys more than would female participants. This hypothesis was tested using the above $2 \times 3$ repeated-measures ANOVA. This hypothesis was supported. For the full sample, the main effect of sex was statistically significant, $F(1,30.34)=30.93, p<.001$, partial eta squared $=.08$. Additionally, the toy type by sex interaction was statistically significant, Wilks' Lambda $=.94, F(2,393)=11.95, p$ $<.001$, multivariate partial eta squared $=.06$. For the prospective parent sample, the main effect of sex was statistically significant, $F(1,30.34)=30.34, p<.001$, partial eta squared $=.08$. Additionally, the toy type by sex interaction was statistically significant, Wilks' Lambda $=.94, F$ $(2,360)=12.01, p<.001$, multivariate partial eta squared $=.06$.

\section{Exploratory analyses.}

Six exploratory analyses were conducted. The first exploratory question was whether classification of participants as either entity theorists or incremental theorists by the implicit theories measure would be related to gender-typing of toys. Because previous research does not suggest a directional hypothesis, a $t$-test was used to determine if the difference between toy gender-typing scores for these two groups was significantly greater than what is expected by chance. This relation was not found. Male participants classified as entity theorists $(M=2.39$, 
$S D=.67)$ did not differ significantly on their toy gender-typing scores from male participants classified as incremental theorists $(M=2.47, S D=.64), t(135)=-.65, p=.52$, nor did female participants classified as entity theorists $(M=2.06, S D=.57)$ differ significantly on their toy gender-typing scores from female participants classified as incremental theorists $(M=2.21, S D=$ $.60), t(141)=-1.47, p=.15$.

The second exploratory question was whether the degree to which participants believed that homosexuality is due to nature was related to gender-typing of toys. A Pearson's productmoment correlation coefficient was calculated using the nature subscale scores of the HBQ-S and toy gender-typing scores. For both male participants, $r(202)=-.26, p<.001$, and female participants, $r(215)=-.25, p<.001$, less belief that the etiology of homosexuality is due to nature was associated with more gender-typed toy ratings.

A standard multiple linear regression analysis was used to estimate the percentage of total variance in toy gender-typing accounted for by each independent variable. Only variables that correlated with toy gender-typing scores at $r>.25$ were included. The dependent variable was the toy gender-typing scores, and the independent variables were participant sex, the combined Modern Homonegativity Scale scores, the transformed nurture scores of the Homosexuality Beliefs Questionnaire scores, the BS and HS subscales of the Ambivalent Sexism Inventory, the Neosexism Scale score, and the transformed Social Dominance Orientation scale score. As previously discussed, the only multicollinearity issues arose from the high correlation between the two subscales of the MHS, which were therefore combined into a single variable.

The total variance explained by the model was $26.2 \%, F(7,409)=20.75, p<.001$. The only two unique statistically significant predictors were homonegativity (beta $=.24, p<.001$ ) and benevolent sexism ( $b e t a=.20, p<.001$ ). Neither the interaction term for participant sex 
and homonegativity (beta $=-.05, p=.26$ ) nor for participant sex and benevolent sexism (beta $=$ $.03, p=.58$ ) were statistically significant (see Table 10 for all regression results).

A cluster analysis was performed to determine whether unique profiles existed among several of the scale scores that differentially predict toy-rating scores. The clustering variables were the combined Modern Homonegativity Scale scores, social dominance orientation, hostile sexism, and benevolent sexism. Hierarchical cluster analysis using Ward's method yielded a two-cluster solution as the best solution, but it also yielded an acceptable four-cluster solution. An iterative analysis was then conducted with a specified four-cluster solution. The four clusters that emerged could be described as moderately low on all variables, low on all variables, high on all variables, and moderately high on all variables (see Figure 1).

A Chi-square analysis revealed that male and female participants differed significantly on their cluster membership, $\chi^{2}(3, N=417)=36.17$, with male participants more likely than female participants to be in the third and fourth clusters and female participants more likely than male participants to be in the first and second clusters. A one-way ANOVA analysis found that the clusters differed significantly on their gender-typed toy rating scores, $F(3,416)=33.21$, $p<.001$. Post-hoc tests revealed that the second and third clusters differed significantly from all other clusters on toy gender-typing, while the first and fourth clusters varied significantly from the first and third clusters, but did not differ significantly from each other.

Due to the gender difference in cluster membership, the analyses were rerun for each gender. For both male and female participants, the hierarchical analysis suggested a threecluster solution. For males, the three clusters that emerged could be described as moderately high on all variables, moderately low on all variables, and slightly high on all variables (see Figure 2). For female participants, the clusters were high on homonegativity and moderately 
high on the others, moderately low on all variables, and near the mean on all four variables. It is interesting to note that, even though these graphs used standardized scores, eliminating scaling issues, the most extreme scores distinguishing the high and low groups for female participants were the combined Modern Homonegativity Scale scores.

A fifth exploratory analysis examined the relations between the five factors of the Big Five inventory, which measures personality traits (John, Donahue, \& Kentle, 1991), and gendertyped toy rating scores (see Table 11). The only significant correlation was between openness and gender-typed toy ratings; individuals who were more open to new experiences rated toys in a less gender-typed way, which means they were more likely to rate toys as appropriate for both boys and girls.

\section{Discussion}

This study established a quantitative link between homonegative and sexist attitudes and one type of gender socialization, gender-typed toys. This link had previously been reported in the literature based on qualitative research methods, such as interviews, in which rationale for discouragement of cross-gender-typed toy play, particularly for young boys, included devaluing femininity and concerns about homosexuality (Kane, 2006). This research area has primarily focused on the beliefs and perceptions of parents; the current study extended this line of work to nonparents, including prospective parents.

The findings that gender-typed toy ratings were related to hostile and benevolent sexism and neosexism lends support to the gender belief system theory (Deaux \& Kite, 1998), showing that individuals' general beliefs about gender are related to their specific beliefs about the gender-appropriateness of toys.. An implication of these findings is that adults who feel more negatively towards homosexual individuals and believe that nurture experience can cause 
homosexuality may choose gender-socialization strategies for children that seek to minimize the risk of later homosexuality.

This study also explored how domain-general constructs related to stereotyping may be related to the gender-typed ratings of toys, which may be construed as an act of stereotyping. It did not find support for the exploratory hypothesis that participants' implicit theories of personality are related to their toy-rating tendencies. The relation between gender-typed toy ratings and social dominance orientation was not significant.

The finding that participants rated stereotypically female-typed toys in a more gendertyped way than stereotypically male-typed toys is congruent with research that has found that adults are more likely to criticize boys than girls for cross-gender-typed behavior (e.g., Hyun \& Tyler, 2000). Previous research has found that fathers rate toys in a more gender-typed way than mothers (Burge, 1981), so the finding that male participants rated toys in a more gendertyped way than female participants in this study suggests that this is a gender difference that exists among non-parents as well.

Exploratory analyses revealed that the nature subscale of the HBQ was also related to gender-typing of toys, suggesting that both sets of beliefs about the etiology of homosexuality, the influence of nature and the influence of nurture, are important for understanding individuals' toy ratings. These two subscales should not be considered multicollinear, however, as they are only correlated at $r=-.27$, which suggests that they are capturing somewhat different dimensions and are not two extremes of a single dimension.

An exploratory multiple regression analysis revealed that the only unique significant predictors of gender-typed toy ratings were homonegativity and benevolent sexism. The results of this regression analysis informs future research by indicating that the chosen variables 
account for a moderate amount of the variance in gender-typed ratings of toys, that there is a high degree of overlap in the variance accounted for by the variables (indicated by the paucity of unique predictors), and that benevolent sexism and homonegativity are the strongest predictors of gender-typed toy ratings. Benevolent sexism is subjectively positive, but homonegativity is subjectively negative, suggesting that both negative emotions such as fear, as well as positive emotions such as regard for women's "traditional" role may both motivate gender socialization strategies, including gender-typing children's toys.

Future studies could explore the motivational link between attitudes and toy beliefs, as well as the link between toy beliefs and behaviors, such as purchasing or encouraging play with certain toys. In a family setting, this means that mothers and fathers may have different beliefs about the gender-appropriateness of toys and other gender socialization strategies even if they're similar on these predictive variables, or mothers and fathers who have similar gender socialization strategies may be motivated by different beliefs.

\section{Limitations.}

\section{Personal attributes questionnaire issues.}

Interestingly, instrumentality and expressiveness, as measured by the two subscales of the Personal Attributes Questionnaire, were not found to be significantly related to gendertyped ratings of toys. The validity of this measure and the Bem Sex Roles Inventory (BSRI), both created in the 1970s, for measuring masculinity and femininity has been called into question in recent years. Critiques include the increasing endorsement of "masculine" traits by female participants (Twenge, 1997), the outdated definition of independence/autonomy as "masculine" (Gill, Stockard, Johnson, \& Williams, 1987), the high loadings of the PAQ onto the Big Five Inventory (Lippa, 1991), and the fact that other dimensions, such as congruence of 
gender identity and flexibility of gender role attitudes, are more important than gender-typed traits for predicting psychological adjustment (DiDonato \& Berenbaum, 2011). The high loadings of the PAQ onto the Big Five Inventory suggests that instrumentality and expressiveness are better defined as personality traits than as gendered traits.

\section{Modern homonegativity scale issues.}

The two subscales of the Modern Homonegativity Scale were administered separately with the expectation that the subscale scores would have significantly different means and may have had different relations with other variables. This expectation was based on previous research, in which it was found that homonegativity toward gay men was stronger than homonegativity toward lesbians (e.g., Schope \& Eliason, 2004).

However, for this sample, although male participants reported significantly more homonegativity than female participants on both subscales (see Table 3), the correlation between the two variables was very high $(r=.93)$. Neither male, $t(201)=1.67, p=.096$, nor female participants, $t(214)=-2.62, p=.010$, had significantly different scores for the lesbian and gay men subscales, leading to the collapsing of these scales into a single scale for these analyses. This finding is surprising in light of past research. This finding may represent a convergence of attitudes toward male and female homosexual individuals, either in the current cohort of emerging adults or in the college student population. An alternative explanation is that because the subscales asked identical questions, varying only in whether they asked about gay men or lesbians, participants may have been motivated by a desire to answer consistently. The two subscale questionnaires were separated by a single other measure, so participants could have remembered their answers to the previous subscale and answered in a consistent way. 


\section{College student sample.}

This study used a college student sample for two reasons. Non-parent adults are often important figures in the lives of young children and can exert considerable influence on their development, as caretakers, preschool teachers, relatives, or friends of the family. Indeed, one study that employed interviews with adults leaving toy stores found that adults reported purchasing more gender-typed toys for other people's children than parents reported purchasing for their own children (Fisher-Thompson, 1993). Additionally, due to the bidirectional influences by which parents and children socialize each other (Karraker \& Coleman, 2005), parents' ratings of the gender-appropriateness of toys may be influenced by their specific interactions with their own children, as noted previously within this literature (Campenni, 1999). Therefore, a non-parent sample seemed to offer a clearer picture of the association between beliefs about the gender-appropriateness of toys and other beliefs, attitudes, and characteristics, as well as giving insight into the beliefs and attitudes of a sample of individuals who are likely to become parents in the relatively near future.

That said, the limitations of using college student and other convenience samples have been widely discussed within behavioral and social science research. A recent paper (Henrich, Heine, \& Norenzayan, 2010) summarized many of the differences between the typical behavioral study sample and the larger human population, noting that behavioral scientists tend to use samples that are disproportionately western, educated, industrialized, rich, and democratic. Besides being non-representative of the larger population in terms of demographics, many studies have shown that college students differ psychologically from the larger population; they have stronger cognitive skills and less crystalized attitudes (e.g., Sears, 1986), as well as different personality traits (e.g., Cooper, McCord, \& Socha, 2010). 
This limitation means that the findings of this study are valuable for understanding this particular population, as well as potentially serving as a starting place for forming hypotheses about other populations of adults. In addition to the importance of understanding this sample as non-parents, most (92.5\%) of our sample indicated that they plan on having children in the future; understanding the beliefs and attitudes of the next cohort of parents before they become parents is of longitudinal interest, as these beliefs and attitudes may impact the parenting choices made by this population in the next few decades.

\section{Conclusion}

This study found that several dimensions of participants' gender belief systems, including hostile sexism, benevolent sexism, neosexism, and beliefs about homosexuality, including homonegativity and beliefs about the etiology of homosexuality, were related to their gender-typed ratings of toys. Male participants rated toys in a more gender-typed way, and female-stereotypical toys were rated in a more gender-typed way than male-stereotypical toys.

Exploratory analyses suggested several future directions for research. Belief that the etiology of homosexuality is nature was related to gender-typed toy ratings; its lack of multicollinearity with the belief that the etiology of homosexuality is nurture suggests that these two constructs are independent. An exploratory multiple regression found that homonegativity and benevolent sexism were the only unique significant predictor.

By examining the correlates of adults' tendency to rate toys in a gender-typed way, this study contributed knowledge about one of the environmental influences that may impact children's play with toys, which in turn has been shown to impact their development in several areas, including gender role, interests, and skills. These associations could be used to guide 
future research in this area, as well as helping researchers to understand which adults are most likely to perpetuate gender stereotypes through their attitudes toward gender-typed toys. 


\section{References}

Becker, J. C., \& Wright, S. C. (2011). Yet another dark side of chivalry: Benevolent sexism undermines and hostile sexism motivates collective action for social change. Journal of Personality and Social Psychology, 101(1), 62-77.

Bem, S. L. (1974). The measurement of psychological androgyny. Journal of Consulting and Clinical Psychology, 42, 155-162.

Bem, S. L. (1981). Gender schema theory: A cognitive account of sex typing source. Psychological Review, 88, 354-364.

Bigler, R. S. (1995). The role of classification skill in moderating environmental influences on children's gender stereotyping: A study of the functional use of gender in the classroom. Child Development, 66, 1072-1087.

Blakemore, J. E. O., Berenbaum, S. A. \& Liben, L. S. (2009). Gender development. New York: Taylor \& Francis.

Blakemore, J., \& Centers, R. E. (2005). Characteristics of boys' and girls' toys. Sex Roles, 53, 619633.

Blakemore, J., \& Hill, C. A. (2008). The Child Gender Socialization Scale: A measure to compare traditional and feminist parents. Sex Roles, 58, 192-207.

Buchner, A., Erdfelder, E., \& Faul, F. (1997). How to Use G*Power [WWW document]. URL http://www.psycho.uniduesseldorf.de/aap/projects/gpower/how_to_use_gpower.html

Burge, P. L. (1981). Parental child-rearing sex-role attitudes related to social issue sex-role attitudes and selected demographic variables. Home Economics Research Journal, 9, 193-199. 
Caldera, Y. M., \& Sciaraffa, M. A. (1998). Parent-toddler play with feminine toys: Are all dolls the same?. Sex Roles, 39, 657-668.

Campenni, C. (1999). Gender stereotyping of children's toys: A comparison of parents and nonparents. Sex Roles, 40, 121-138.

Cherney, I. D. (2008) Mom, let me play more computer games: They improve my mental rotation skills. Sex Roles, 59, 776-786.

Cherney, I. D., \& Dempsey, J. (2010). Young children's classification, stereotyping and play behavior for gender neutral and ambiguous toys. Educational Psychology, 30, 651669.

Cherney, I. D., Kelly-Vance, L., Glover, K., Ruane, A., \& Ryalls, B. (2003). The effects of stereotyped toys and gender on play assessment in children aged 18-47 months. Educational Psychology, 23(1), 95-105.

Chick, K., Heilman-Houser, R., \& Hunter, M. (2002). The impact of child care on gender role development and gender stereotypes. Early Childhood Education Journal, 29, 149-154.

Chiu, C., Hong, Y., \& Dweck, C. S. (1997). Lay dispositionism and implicit theories of personality. Journal of Personality and Social Psychology, 73(1), 19-30.

Christopher, A. N., \& Mull, M. S. (2006). Conservative ideology and ambivalent sexism. Psychology of Women Quarterly, 30, 223-230.

Crowne, D. P., \& Marlowe, D. (1960). A new scale of social desirability independent of psychopathology. Journal Of Consulting Psychology, 24, 349-354.

Deaux, K., and Kite, M. E. (1987). Thinking about gender. In B. B. Hess and M. M. Ferree (Eds.), Analyzing gender: A handbook of social science research (pp. 92-117). Newbury 
Park, CA: Sage.

Doyle, R. A., Voyer, D., \& Cherney, I. D. (2012). The relation between childhood spatial activities and spatial abilities in adulthood. Journal Of Applied Developmental Psychology, 33(2), 112-120.

Dweck, C. S., Chiu, C., \& Hong, Y. (1995). Implicit theories and their role in judgments and reactions: A world from two perspectives. Psychological Inquiry, 6, 267-285.

Eldridge, J., \& Johnson, P. (2011). The relationship between old-fashioned and modern heterosexism to social dominance orientation and structural violence. Journal of Homosexuality, 58, 382-401.

Fagot, B. I., Leinbach, M. D., \& O'Boyle, C. (1992). Gender labeling, gender stereotyping, and parenting behaviors. Developmental Psychology, 28, 225-230.

Fisher-Thompson, D. (1990). Adult sex typing of children's toys. Sex Roles, 23(5-6), 291-303.

Fisher-Thompson, D. (1993). Adult toy purchases for children: Factors affecting sex-typed toy selection. Journal of Applied Developmental Psychology, 14, 385-406.

Freeman, N. K. (2007). Preschoolers' perceptions of gender appropriate toys and their parents' beliefs about genderized behaviors: Miscommunication, mixed messages, or hidden truths?. Early Childhood Education Journal, 34, 357-366.

Glick, P., Fiske, S. T., Mladinic, A., Saiz, J. L., Abrams, D., Masser, B., \& ... López, W. (2000). Beyond prejudice as simple antipathy: Hostile and benevolent sexism across cultures. Journal of Personality and Social Psychology, 79, 763-775. 
Glick, P., \& Fiske, S. T. (1997). Hostile and benevolent sexism: Measuring ambivalent sexist attitudes toward women. Psychology of Women Quarterly, 21, 119-135.

Green, V. A., Bigler, R., \& Catherwood, D. (2004). The variability and flexibility of gender-typed toy play: A close look at children's behavioral responses to counterstereotypic models. Sex Roles, 51, 371-386.

Howell, D. (2010). Statistical methods for psychology. (7 ed.). Belmont, CA: Wadsworth, Cengage Learning.

Hupp, J. M., Smith, J. L., Coleman, J. M., \& Brunell, A. B. (2010). That's a boy's toy: Gender-typed knowledge in toddlers as a function of mother's marital status. The Journal of Genetic Psychology: Research and Theory on Human Development, 171, 389-401.

Hyun, E., \& Tyler, M. (2000). Examination of early childhood practitioners' general perceptions of gender differences in young children. Journal of Early Childhood Teacher Education, $21,337-354$.

Jadva, V., Hines, M., \& Golombok, S. (2010). Infants' preferences for toys, colors, and shapes: Sex differences and similarities. Archives of Sexual Behavior, 39, 1261-1273.

John, O. P., Donahue, E. M., \& Kentle, R. L. (1991). The Big Five Inventory--Versions $4 a$ and 54. Berkeley, CA: University of California, Berkeley, Institute of Personality and Social Research.

Kane, E. W. (2006). 'No Way My Boys are Going to be Like That!': Parents' Responses to Children's Gender Nonconformity. Gender \& Society, 20(2), 149-176.

Kite, M. E., \& Deaux, K. (1987). Gender belief systems: Homosexuality and the implicit inversion theory. Psychology of Women Quarterly, 11(1), 83. 
Knafo, A. (2003), Authoritarians, the next generation: Values and bullying among adolescent children of authoritarian fathers. Analyses of Social Issues and Public Policy, 3, 199-204.

Leaper, C. (2000). Gender, affiliation, assertion, and the interactive context of parent-child play. Developmental Psychology, 36, 381-393.

Leaper, C., \& Friedman, C. (2007). The Socialization of Gender. In J. E. Grusec, P. D. Hastings (Eds.) , Handbook of socialization: Theory and research (pp. 561-587). New York, NY US: Guilford Press.

Levy, S. R., Stroessner, S. J., \& Dweck, C. S. (1998). Stereotype formation and endorsement: The role of implicit theories. Journal of Personality and Social Psychology, 74, 1421-1436.

LoBue, V., \& DeLoache, J. S. (2011). Pretty in pink: The early development of genderstereotyped colour preferences. British Journal of Developmental Psychology, 29, 656-667.

Maccoby, E. E. (1998). The two sexes: Growing up apart, coming together. Cambridge, MA: Harvard University Press.

Martinez, C., Paterna, C., Roux, P., \& Falomir, J. (2010). Predicting gender awareness: the relevance of neo-sexism. Journal of Gender Studies, 19(1), 1-12.

Mehta, C. M., \& Strough, J. (2009). Sex segregation in friendships and normative contexts across the life span. Developmental Review, 29, 201-220.

Miller, C. L. (1987). Qualitative differences among gender-stereotyped toys: Implications for cognitive and social development in girls and boys. Sex Roles, 16, 473-487.

Moller, L. C., \& Serbin, L. A. (1996). Antecedents of toddler gender segregation: Cognitive consonance, gender-typed toy preferences and behavioral compatibility. Sex Roles, 35, 445-460. 
Montañés, P., de Lemus, S., Bohner, G., Megías, J. L., Moya, M., \& Garcia-Retamero, R. (2012). Intergenerational transmission of benevolent sexism from mothers to daughters and its relation to daughters' academic performance and goals. Sex Roles, 66, 468-478.

Morrison, M.A. \& Morrison, T.G. (2002). Development and validation of a scale measuring modern prejudice toward gay men and lesbian women. Journal of Homosexuality, 43(2), 15-37.

O'Brien, M., \& Huston, A. (1985). Activity level and sex-stereotyped toy choice in toddler boys and girls. The Journal of Genetic Psychology, 146, 527-533.

Peretti, P. O., \& Sydney, T. M. (1984). Parental toy choice stereotyping and its effects on child toy preference and sex-role typing. Social Behavior and Personality, 12, 213-216.

Peterson, B. E. and Zurbriggen, E. L. (2010), Gender, sexuality, and the authoritarian personality. Journal of Personality, 78, 1801-1826.

Pomerleau, A., Bolduc, D., Malcuit, G., \& Cossette, L. (1990). Pink or blue: Environmental gender stereotypes in the first two years of life. Sex Roles, 22, 359-367.

Pratto, F., Sidanius, J., Stallworth, L. M., \& Malle, B. F. (1994). Social dominance orientation: A personality variable predicting social and political attitudes. Journal of Personality and Social Psychology, 67, 741-763.

Raag, T. (1999). Influences of social expectations of gender, gender stereotypes, and situational constraints on children's toy choices. Sex Roles, 41, 809-831.

Raag, T., \& Rackliff, C. L. (1998). Preschoolers' awareness of social expectations of gender: Relationships to toy choices. Sex Roles, 38, 685-700.

Rheingold, H. L., \& Cook, K. V. (1975). The contents of boys' and girls' rooms as an index of parents' behavior. Child Development, 46, 459-463. 
Schope, R. D., \& Eliason, M. J. (2004). Sissies and tomboys: Gender role behaviors and homophobia. Journal of Gay \& Lesbian Social Services: Issues In Practice, Policy \& Research, 16(2), 73-97.

Rye, B.J., \& Meaney, G.J. (2010). Self-defense, sexism, and etiological beliefs: Predictors of attitudes toward gay and lesbian adoption. Journal of GLBT Family Studies, 6, 1-24.

Serbin, L. A., \& Connor, J. M. (1979). Sex-typing of children's play preferences and patterns of cognitive performance. Journal of Genetic Psychology, 134, 315.

Serbin, L. A., Poulin-Dubois, D., Colburne, K. A., Sen, M. G., \& Eichstedt, J. A. (2001). Gender stereotyping in infancy: Visual preferences for and knowledge of gender-stereotyped toys in the second year. International Journal of Behavioral Development, 25(1), 7-15.

Shakin, M., Shakin, D., \& Sternglanz, S. H. (1985). Infant clothing: Sex labeling for strangers. Sex Roles, 12, 955-964.

Sheldon, J. P., Pfeffer, C. A., Jayaratne, T., Feldbaum, M., \& Petty, E. M. (2007). Beliefs about the etiology of homosexuality and about the ramifications of discovering its possible genetic origin. Journal of Homosexuality, 52, 111-150.

Smith, T. P. (2002). Age determination guidelines: Relating children's ages to toy characteristics and play behavior. Washington, D.C.: United States Consumer Product Safety Commission.

Smith, S. J., Zanotti, D. C., Axelton, A. M., \& Saucier, D. A. (2011). Individuals' beliefs about the etiology of same-sex sexual orientation. Journal of Homosexuality, 58, 1110-1131. 
Spence, I., \& Feng, J. (2010). Video games and spatial cognition. Review of General Psychology, 14(2), 92-104.

Spence, J. T. (1980). The psychological dimensions of masculinity and femininity and achievement motivation. Annals of the New York Academy of Sciences, 340, 88-101.

Spence, J. T., \& Buckner, C. E. (2000). Instrumental and expressive traits, trait stereotypes, and sexist attitudes. Psychology of Women Quarterly, 24(1), 44.

Spence, J.T., Helmreich, R.L., \& Stapp, J. (1974). The personal attributes questionnaire: A measure of sex role stereotypes and masculinity-femininity. JSAS Catalog of Selected Documents in Psychology, 4, 43.

Tabachnick, B.G. \& Fidell, L.S. (2013). Using Multivariate Statistics, 6/e. New York: HarperCollins.

Tougas, F., Brown, R., Beaton, A. M., \& Joly, S. (1995).Neosexism: Plus ca change, plus c'est pareil. Personality and Social Psychology Bulletin, 21, 842-849.

Tracy, D. M. (1987). Toys, spatial ability, and science and mathematics achievement: Are they related?. Sex Roles, 17, 115-138.

Trawick-Smith, J., Russell, H., \& Swaminathan, S. (2011). Measuring the effects of toys on the problem-solving, creative and social behaviors of preschool children. Early Child Development and Care, 181, 909-927.

Unger, R. (1979). Toward a redefinition of sex and gender. American Psychologist, 34, 10851094. 
Wai, J., Lubinski, D., \& Benbow, C. P. (2009). Spatial ability for STEM domains: Aligning over 50 years of cumulative psychological knowledge solidifies its importance. Journal of Educational Psychology, 101, 817-835.

Weinraub, M. (1984). The development of sex role stereotypes in the third year: Relationships to gender labeling, gender identity, sex-typed toy preference, and family characteristics. Child Development, 55, 1493-1503.

Wilansky-Traynor, P., \& Lobel, T. E. (2008). Differential effects of an adult observer's presence on sex-typed play behavior: A comparison between gender-schematic and genderaschematic preschool children. Archives of Sexual Behavior, 37, 548-557.

Whitley, B. R. (2001). Gender-role variables and attitudes toward homosexuality. Sex Roles, $45,691-721$.

Whitley, B. R., \& AEgisdóttir, S. (2000). The gender belief system, authoritarianism, social dominance orientation, and heterosexuals' attitudes toward lesbians and gay men. Sex Roles, 42, 947-967.

Wood, E., Desmarais, S., \& Gugula, S. (2002). The impact of parenting experience on gender stereotyped toy play of children. Sex Roles, 47, 39-49. 
Appendix A

Demographic Questionnaire

Please complete the following items.

1. Age:

2. Gender:

Male
Female

3. Year in college:

$1^{\text {st }}$ year
$2^{\text {nd }}$ year
$3^{\text {rd }}$ year
$4^{\text {th }}$ year

4. Race:

Caucasian
African-American
Native American
Hispanic
Other:

5. Sexual Orientation:

Heterosexual
Homosexual
Bisexual
Other

6. Marital status:

Married
Not married
Cohabitating

7. Do you have any children?

Yes
No


If no, do you plan to someday have children?

Yes
No
Maybe

8. How would you characterize your political beliefs?

Very liberal
Liberal
Moderate
Conservative
Very conservative

9. How religious do you consider yourself?

$\begin{array}{llllllllll}\text { Not religious at all } & 1 & 2 & 3 & 4 & 5 & 6 & 7 & \text { Very religious }\end{array}$

10. During the past year, how frequently have you had contact with infants (birth to 2 years), on average?

At least once a week At least once a month Rarely Not at all

11. During the past year, how frequently have you had contact with young children (2-5 years), on average?

At least once a week
At least once a month
Rarely
Not at all

12. How much do you like infants? Much more than average More than average Average Less than average Much less than average

13. How much do you like young children? 
Much more than average

More than average

Average

Less than average

Much less than average

14. Do you have any younger siblings?

Yes

15. What is your father's highest level of education?

some high school

high school diploma/GED some college or Associate's degree Bachelor's degree some graduate/professional school graduate or professional degree

16. What is your mother's highest level of education? some high school high school diploma/GED some college or Associate's degree Bachelor's degree some graduate/professional school graduate or professional degree 


\section{Appendix B}

Toy Rating Task

\section{For which children is a baby doll most appropriate?}

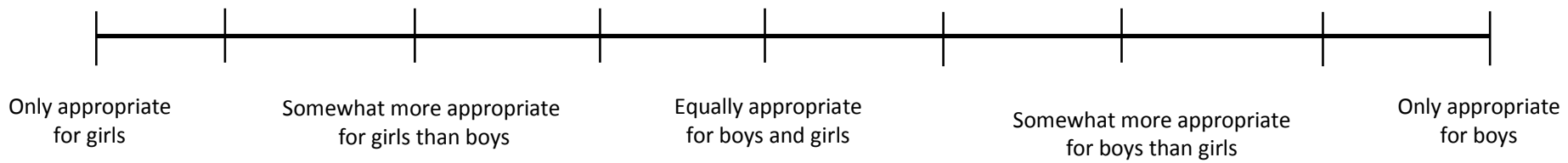

\section{For which children is a large truck most appropriate?}

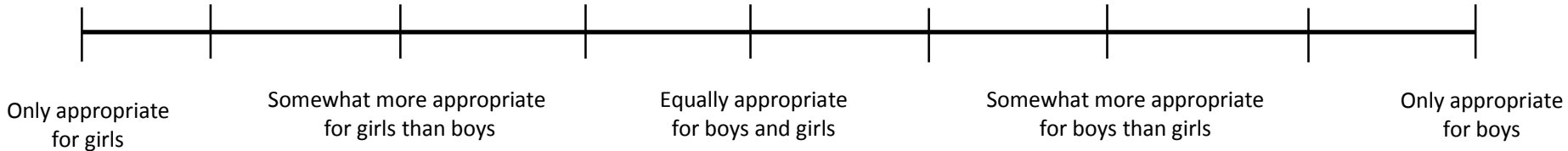

3. For which children is a simple story-reading program most appropriate?

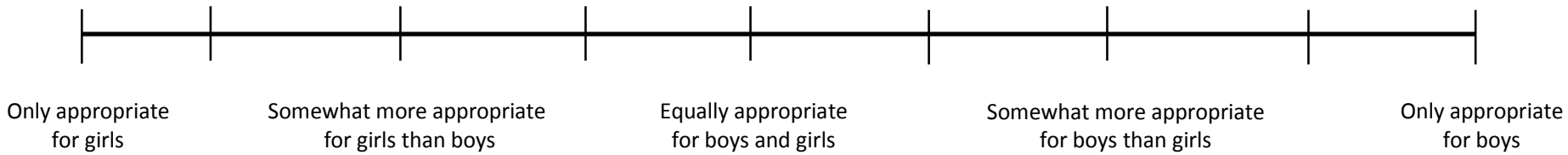

4. For which children is a train with 2-6 cars most appropriate?

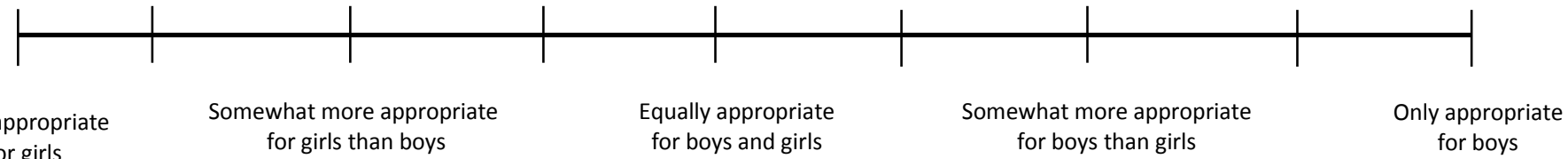

5. For which children is soft modeling clay or dough (i.e. PlayDoh) most appropriate?

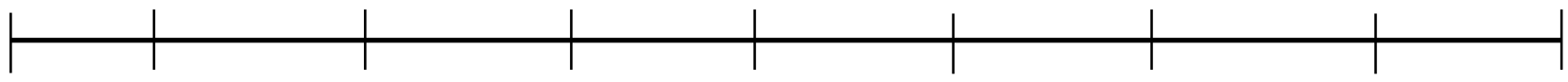

Only appropriate for girls
Somewhat more appropriate for girls than boys
Equally appropriate for boys and girls
Somewhat more appropriate for boys than girls
Only appropriate for boys

6. For which children are dress-up clothes most appropriate?

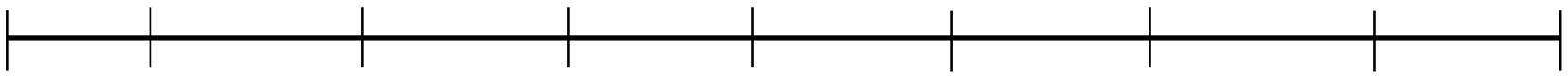

Only appropriate for girls
Somewhat more appropriate for girls than boys
Equally appropriate for boys and girls
Somewhat more appropriate for boys than girls
Only appropriate for boys 
7. For which children is software that teaches colors, shapes, letters, sounds, and numbers most appropriate?

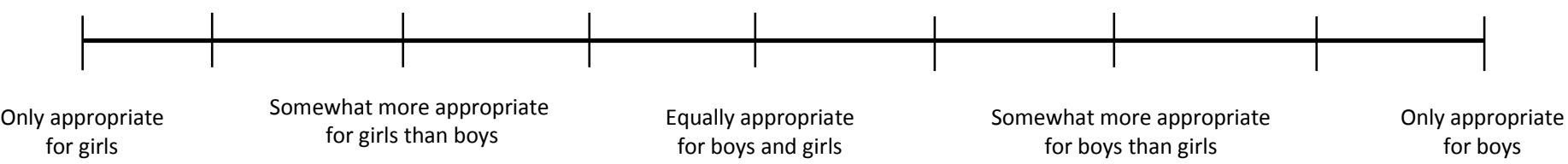

8. For which children is a simple dress-me doll most appropriate?

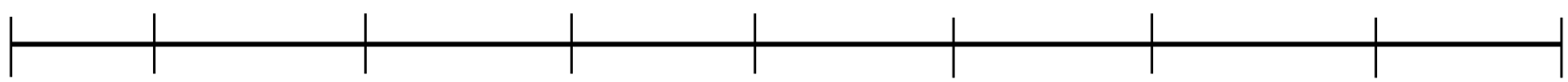

Only appropriate for girls
Somewhat more appropriate for girls than boys
Equally appropriate for boys and girls
Somewhat more appropriate for boys than girls
Only appropriate for boys

9. For which children is a toy lawnmower most appropriate?

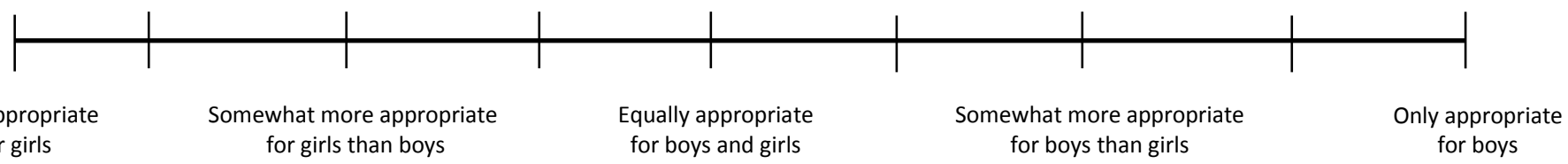


Appendix C

Modern Homonegativity Scale

Many gay men/lesbian women use their sexual orientation so that they can obtain special privileges.

1

Strongly disagree
2
3

Neither Agree Nor Disagree
4

5

Strongly Agree

Gay men/lesbian women seem to focus on the ways in which they differ from heterosexuals, and ignore the ways in which they are the same.

1

Strongly disagree
2

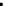

Neither Agree Nor Disagree
4

5

Strongly Agree

Gay men/lesbian women do not have all the rights they need.*
1 2
3
4
5
Strongly disagree
Neither Agree Nor Disagree
Strongly Agree

The notion of universities providing students with undergraduate degrees in Gay and Lesbian Studies is ridiculous.
1
2
3
4
5
Strongly disagree
Neither Agree Nor Disagree
Strongly Agree

Celebrations such as Gay Pride Day are ridiculous because they assume that an individual's sexual orientation should constitute a source of pride.
1
2
3
4
5
Strongly disagree
Neither Agree Nor Disagree
Strongly Agree

Gay men/lesbian women still need to protest for equal rights.*

$\begin{array}{llcll}1 & 2 & 3 & 4 & 5 \\ \text { Strongly disagree } & & \text { Neither Agree Nor Disagree } & & \text { Strongly Agree }\end{array}$

Gay men/lesbian women should stop shoving their lifestyle down other people's throats.

1

Strongly disagree
2

Neither Agree Nor Disagree
5

Strongly Agree 
If gay men/lesbian women want to be treated like everyone else, then they need to stop making such a fuss about their sexuality/culture.

1

Strongly disagree
2

3

Neither Agree Nor Disagree
4

5 Strongly Agree

Gay men/lesbian women who are "out of the closet" should be admired for their courage.*

$\begin{array}{llcll}1 & 2 & 3 & 4 & 5 \\ \text { Strongly disagree } & & \text { Neither Agree Nor Disagree } & & \text { Strongly Agree }\end{array}$

Gay men/lesbian women should stop complaining about the way they are treated in society, and simply get on with their lives.

1

Strongly disagree
2

(1)
Neither Agree Nor Disagree
45
Strongly Agree

In today's tough economic times, Americans' tax dollars shouldn't be used to support gay men's/lesbian women's organizations.
1
2
3
4
5
Strongly disagree
Neither Agree Nor Disagree
Strongly Agree

Gay men/lesbian women have become far too confrontational in their demand for equal rights.

$\begin{array}{lcccc}1 & 2 & 3 & 4 & 5 \\ \text { Strongly disagree } & & \text { Neither Agree Nor Disagree } & & \text { Strongly Agree } \\ * \text { Reverse scored } & & & \end{array}$


Appendix D

Homosexuality Beliefs Questionnaire- Short Form

Please use the 9-point scale below to indicate your agreement with each statement.

Disagree Very Strongly

$\begin{array}{llllll}4 & 5 & 6 & 7 & 8 & 9\end{array}$

Agree Very Strongly

Nurture

Homosexuality is a result of encouragement from adults and peers.

A lack of exposure to religion in children makes people more likely to be homosexual.

Homosexuality is a result of an undercontrolled childhood.

Individuals who have more stressors and pressures put on them may become homosexual as a result.

Children raised without clear gender roles are more likely to be homosexual.

Homosexuality is a result of peer pressure.

Those who were raised in strict households are more likely to be homosexual.

Those who feel rejected often will become homosexual.

People become homosexual as a result of poor peer relationships growing up.

Homosexuality is a result of submissive fathers.

Homosexuality is a result of an overcontrolled childhood.

People who wish to rebel against their religion become homosexuals.

Having a dysfunctional family is a cause of homosexuality.

Nature

People are not born homosexual.*

Homosexuality is caused by differences in the brain's organization.

Homosexuality is not caused by genetics.*

Homosexuality is caused by differences in one's brain structure.

Homosexuality is a choice.*

A person is homosexual his/her whole life.

Homosexuality is biological.

People are born homosexual.

Homosexuality is caused by genetics.

Homosexuality is not a choice.

*Reverse-scored 
Appendix $\mathrm{E}$

Ambivalent Sexism Inventory

Relationships Between Men and Women

Below is a series of statements concerning men and women and their relationships in contemporary society. Please indicate the degree to which you agree or disagree with each statement using the following scale:

0 = disagree strongly; 1 = disagree somewhat; 2 = disagree slightly; 3 = agree slightly; 4 = agree somewhat; 5 = agree strongly.

1. No matter how accomplished he is, a man is not truly complete as a person unless he has the love of a woman. (BS)

2. Many women are actually seeking special favors, such as hiring policies that favor them over men, under the guise of asking for "equality." (HS)

3. In a disaster, women ought not necessarily to be rescued before men.*(BS)

4. Most women interpret innocent remarks or acts as being sexist. (HS)

5. Women are too easily offended. (HS)

6. People are often truly happy in life without being romantically involved with a member of the other sex.* (BS)

7. Feminists are not seeking for women to have more power than men.* (HS)

8. Many women have a quality of purity that few men possess. (BS)

9. Women should be cherished and protected by men. (BS)

10. Most women fail to appreciate fully all that men do for them. (HS)

11. Women seek to gain power by getting control over men. (HS)

12. Every man ought to have a woman whom he adores. (BS)

13. Men are complete without women.* (BS)

14. Women exaggerate problems they have at work. (HS)

15. Once a woman gets a man to commit to her, she usually tries to put him on a tight leash. (HS)

16. When women lose to men in a fair competition, they typically complain about being discriminated against. (HS)

17. A good woman should be set on a pedestal by her man. (BS)

18. There are actually very few women who get a kick out of teasing men by seeming

sexually available and then refusing male advances.* (HS)

19. Women, compared to men, tend to have a superior moral sensibility. (BS)

20. Men should be willing to sacrifice their own well-being in order to provide financially

for the women in their lives. (BS)

21. Feminists are making entirely reasonable demands of men.* (HS)

22. Women, as compared to men, tend to have a more refined sense of culture and good taste. (BS)

*Reverse scored 
Appendix $\mathrm{F}$

Personal Attributes Questionnaire

The items below inquire about what kind of person you think you are. Each item consists of a PAIR of characteristics, with the letters A-E in between. For example,

Not at all artistic A.........................E Very artistic

Each pair describes contradictory characteristics - that is, you cannot be both at the same time, such as very artistic and not at all artistic.

The letters form a scale between the two extremes. You are to choose a letter which describes where YOU fall on the scale. For example, if you think that you have no artistic ability, you would choose A. If you think that you are pretty good, you might choose D. If you are only medium, you might choose $\mathrm{C}$, and so forth.

\begin{tabular}{|c|c|c|c|c|}
\hline$M-F$ & 1. & Not at all aggressive & A $\ldots \ldots \ldots$ B.................E & Very aggressive \\
\hline$M$ & 2. & Not at all independent & A.......................E & Very independent \\
\hline $\mathrm{F}$ & 3. & Not at all emotional & A..................D.....E & Very emotional \\
\hline$M-F$ & 4. & Very submissive & A......В................E & Very dominant \\
\hline$M-F$ & 5. & $\begin{array}{l}\text { Not at all excitable in a } \\
\text { major crisis }\end{array}$ & A......В................E & $\begin{array}{l}\text { Very excitable in a major } \\
\text { crisis }\end{array}$ \\
\hline$M$ & 6. & Very passive & A......В................E & Very active \\
\hline $\mathrm{F}$ & 7. & $\begin{array}{l}\text { Not at all able to devote } \\
\text { self completely to others }\end{array}$ & A ................D.....E & $\begin{array}{l}\text { Able to devote self } \\
\text { completely to others }\end{array}$ \\
\hline $\mathrm{F}$ & 8. & Very rough & A......В...........D.....E & Very gentle \\
\hline $\mathrm{F}$ & 9. & $\begin{array}{l}\text { Not at all helpful to } \\
\text { others }\end{array}$ & A......B..........D.....E & Very helpful to others \\
\hline$M$ & 10. & Not at all competitive & A .......................E & Very competitive \\
\hline $\mathrm{M}-\mathrm{F}$ & 11. & Very home oriented & А......................E & Very worldly \\
\hline $\mathrm{F}$ & 12. & Not at all kind & A......В................E & Very kind \\
\hline$M-F$ & 13. & $\begin{array}{l}\text { Indifferent to others' } \\
\text { approval }\end{array}$ & A......В..........D.....E & $\begin{array}{l}\text { Highly needful of others' } \\
\text { approval }\end{array}$ \\
\hline $\mathrm{M}-\mathrm{F}$ & 14. & Feelings not easily hurt & A .......................E & Feelings easily hurt \\
\hline $\mathrm{F}$ & 15. & $\begin{array}{l}\text { Not at all aware of } \\
\text { feelings of others }\end{array}$ & A .......................E & $\begin{array}{l}\text { Very aware of feelings of } \\
\text { others }\end{array}$ \\
\hline M & 16. & Can make decisions easily & A......В...............E & $\begin{array}{l}\text { Has difficulty making } \\
\text { decisions }\end{array}$ \\
\hline M & 17. & Gives up very easily & A.......................E & Never gives up easily \\
\hline$M-F$ & 18. & Never cries & A ........................E & Cries very easily \\
\hline M & 19. & Not at all self-confident & A......B...........D.....E & Very self-confident \\
\hline M & 20. & Feels very inferior & A .......................E & Feels very superior \\
\hline $\mathrm{F}$ & 21. & $\begin{array}{l}\text { Not at all understanding } \\
\text { of others }\end{array}$ & 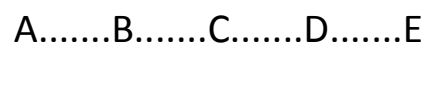 & $\begin{array}{l}\text { Very understanding of } \\
\text { others }\end{array}$ \\
\hline
\end{tabular}


F 22. Very cold in relations with A..........................E Very warm in relations with others others

\begin{tabular}{|c|c|c|c|c|}
\hline$M-F$ & 23. & Very little need for security & A $\ldots \ldots$. B............D.....E & $\begin{array}{l}\text { Very strong need for } \\
\text { security }\end{array}$ \\
\hline M & 24. & $\begin{array}{l}\text { Goes to pieces under } \\
\text { pressure }\end{array}$ & 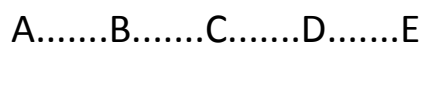 & $\begin{array}{l}\text { Stands up well under } \\
\text { pressure }\end{array}$ \\
\hline
\end{tabular}

Masculine - Feminine $(\mathrm{MF})=$ Androgyny

Masculine $(M)=$ Instrumental

Feminine $(\mathrm{F})=$ Expressive 
Appendix G

Neosexism Scale

Please use the 7-point scale below to indicate your agreement with each statement.

12

Strongly Disagree
3

4

5
6

Strongly Agree

1. Discrimination against women in the labor force is no longer a problem in the USA.

2. I consider the present employment system to be unfair to women.*

3. Women shouldn't push themselves where they are not wanted.

4. Women will make more progress by being patient and not pushing too hard for change.

5. It is difficult to work for a female boss.

6. Women's requests in terms of equality between the sexes are simply exaggerated.

7. Over the past few years, women have gotten more from the government than they deserve.

8. Universities are wrong to admit women into costly programs such as medicine, when in fact, a large number will leave their jobs after a few years to raise their children.

9. In order to not appear sexist, many men are inclined to overcompensate women.

10. Due to social pressures, firms frequently have to hire underqualified women.

11. In a fair employment system, men and women would be considered equal.*

*Reverse scored 
Appendix $\mathrm{H}$

Social Dominance Orientation Scale

Which of the following objects or statements do you have a positive or negative feeling toward?

$\begin{array}{lllllcc}1 & 2 & 3 & 5 & 6 & 6 & 7 \\ \text { Very Negative } & & & & & \text { Very Positive }\end{array}$

1. Some groups of people are simply inferior to other groups.

2. In getting what you want, it is sometimes necessary to use force against other groups.

3. It's OK if some groups have more of a chance in life than others.

4. To get ahead in life, it is sometimes necessary to step on other groups.

5. If certain groups stayed in their place, we would have fewer problems.

6. It's probably a good thing that certain groups are at the top and other groups are at the bottom.

7. Inferior groups should stay in their place.

8. Sometimes other groups must be kept in their place.

9. It would be good if groups could be equal.*

10. Group equality should be our ideal.*

11. All groups should be given an equal chance in life.*

12. We should do what we can to equalize conditions for different groups.*

13. Increased social equality. ${ }^{*}$

14. We would have fewer problems if we treated people more equally.*

15. We should strive to make incomes as equal as possible.*

16. No one group should dominate in society.* 


\section{Appendix I}

Measure of Implicit Theory

Please use the 6-point scale below to indicate your agreement with each statement.

12

Very Strongly Disagree
3

4
5

\section{Very Strongly Agree}

1. The kind of person someone is is something basic about them, and it can't be changed very much.

2. People can do things differently, but the important parts of who they are can't really be changed.

3. Everyone is a certain kind of person, and there is not much that they can do to really change that. 
Appendix J

Big Five Personality Inventory

Here are a number of characteristics that may or may not apply to you. For example, do you agree that you are someone who likes to spend time with others? Please choose a number for each statement to indicate the extent to which you agree or disagree with that statement.

\begin{tabular}{|c|c|c|c|c|}
\hline Disagree Strongly & Disagree a little & $\begin{array}{c}\text { Neither agree } \\
\text { nor disagree }\end{array}$ & Agree a little & Agree Strongly \\
\hline
\end{tabular}

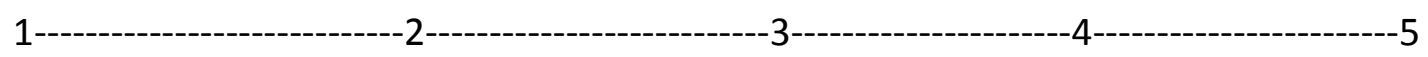

I see myself as someone who:

1. is talkative

2. tends to find fault with others

3. does a thorough job

4. is depressed, blue

5. is original, comes up with new ideas

6. is reserved

7. is helpful and unselfish with others

8. can be somewhat careless

9. is relaxed, handles stress well

10. is curious about many different things

11. is full of energy

12. starts quarrels with others

13. is a reliable worker

14. can be tense

15. is ingenious, a deep thinker

them

16. generates a lot of enthusiasm

17. has a forgiving nature

18. tends to be disorganized

19. worries a lot

20. has an active imagination

21. tends to be quiet

22. is generally trusting

23. tends to be lazy
24. is emotionally stable, not easily upset

25. is inventive

26. has an assertive personality

27. can be cold and aloof

28. perseveres until the task is finished

29. can be moody

30. values artistic, aesthetic experiences

31 . is sometimes intimidated

32 . is considerate and kind to almost everyone

33. does things efficiently

34. remains calm in tense situations

35. prefers work that is routine

36. is outgoing, sociable

37. is sometimes rude to others

38. makes plans and follows through with

39. gets nervous easily

40. likes to reflect, play with ideas

41. has few artistic interests

42. likes to cooperate with others

43. is easily distracted

44. is sophisticated in art, music, and literature 


\section{Appendix K \\ Crowne-Marlowe Social Desirability Scale}

Listed below are a number of statements concerning personal attitudes and traits.

Please read each item and decide whether the statement is true or false as it applies to you. For each item, please circle TRUE or FALSE.

1. Before voting I thoroughly investigate the qualifications of all the candidates. TRUE or FALSE

2. I never hesitate to go out of my way to help someone in trouble. TRUE or FALSE

3. *It is sometimes hard for me to go on with my work if I am not encouraged. TRUE or FALSE

4. I have never intensely disliked anyone. TRUE or FALSE

5. * On occasion I have had doubts about my ability to succeed in life. TRUE or FALSE

6. ${ }^{*}$ I sometimes feel resentful when I don't get my way. TRUE or FALSE

7. I am always careful about my manner of dress. TRUE or FALSE

8. My table manners at home are as good as when I eat out at a restaurant. TRUE or FALSE

9. *If I could get into a movie without paying and be sure I was not seen I would probably do it. TRUE or FALSE

10. * On a few occasions I have given up doing something because I thought too little of my ability. TRUE or FALSE

11. *I like to gossip at times. TRUE or FALSE

12. *There have been times when I felt like rebelling against people in authority, even though I knew they were right. TRUE or FALSE

13. No matter who I'm talking to, I'm always a good listener. TRUE or FALSE

14. *I can remember "playing sick" to get out of something. TRUE or FALSE

15. *There have been occasions when I took advantage of someone. TRUE or FALSE

16. I am always willing to admit when I made a mistake. TRUE or FALSE

17. I always try to practice what I preach. TRUE or FALSE

18. I don't find it particularly difficult to get along with loud-mouthed, obnoxious people. TRUE or FALSE

19. ${ }^{*}$ I sometimes try to get even rather than forgive and forget. TRUE or FALSE

20. When I don't know something, I don't mind at all admitting it. TRUE or FALSE

21. I am always courteous, even to people who are disagreeable. TRUE or FALSE

22. *At times I have really insisted on having things my own way. TRUE or FALSE

23. *There have been occasions when I felt like smashing things. TRUE or FALSE

25. I never resent being asked to return a favor. TRUE or FALSE

26. I have never been irked when people expressed ideas very different from my own. TRUE or FALSE

27. I never make a long trip without checking the safety of my car. TRUE or FALSE

28. *There have been times when I was quite jealous of the good fortune of others. TRUE or FALSE

29. I have almost never felt the urge to tell someone off. TRUE or FALSE

30. *I am sometimes irritated by people who ask favors of me. TRUE or FALSE

31. I have never felt that I was punished without cause. TRUE or FALSE 
32. *I sometimes think when people have a misfortune they only got what they deserved. TRUE or FALSE

33. I have never deliberately said something that hurt someone's feelings. TRUE or FALSE 


\section{TABLES}

Table 1. Descriptive Statistics for Individual Toy Ratings by Gender of Participant.

\begin{tabular}{cccccccccc}
\hline & \multicolumn{2}{c}{ Mean } & \multicolumn{2}{c}{ Standard Deviation } & Minimum & \multicolumn{2}{c}{ Maximum } \\
\hline & Male & Female & Male & Female & Male & Female & Male & Female \\
\hline Baby Doll & 3.68 & 3.26 & 1.27 & 1.25 & 1 & 1 & 5 & 5 \\
\hline Large Truck & 3.09 & 2.52 & 1.25 & 1.21 & 1 & 1 & 5 & 5 \\
\hline Story-Reading Program & 1.05 & 1.03 & .36 & .31 & 1 & 1 & 5 & 5 \\
\hline Train & 2.34 & 2.04 & 1.22 & 1.02 & 1 & 1 & 5 & 5 \\
\hline Play-Doh & 1.13 & 1.02 & .57 & .17 & 1 & 1 & 5 & 3 \\
\hline Dress-up Clothes & 3.02 & 2.69 & 1.33 & 1.31 & 1 & 1 & 5 & 5 \\
\hline Teaching Software & 1.03 & 1.00 & .22 & .069 & 1 & 1 & 3 & 2 \\
\hline Dress-Me Doll & 3.81 & 3.45 & 1.20 & 1.27 & 1 & 1 & 5 & 5 \\
\hline Toy Lawnmower & 2.77 & 2.22 & 1.37 & 1.17 & 1 & 1 & 5 & 5 \\
\hline
\end{tabular}


Table 2. Demographic Characteristics of Study Participants $(N=420)$ by Sex

\begin{tabular}{|c|c|c|c|}
\hline Characteristic & Male $(n=202)$ & Female $(n=215)$ & Comparison \\
\hline Mean age (Standard Deviation) & $19.40(1.64)$ & $19.07(1.55)$ & $t(407.56)=2.12$ \\
\hline Year in College & & & $\chi^{2}(4, N=411)=3.91$ \\
\hline 1 & 80 & 90 & \\
\hline 2 & 59 & 67 & \\
\hline 3 & 40 & 33 & \\
\hline 4 & 14 & 21 & \\
\hline 5 & 5 & 2 & \\
\hline Race & & & $\chi^{2}(5, N=417)=4.98$ \\
\hline Caucasian & 183 & 203 & \\
\hline African-American & 2 & 1 & \\
\hline Asian & 9 & 4 & \\
\hline Native American & 1 & 1 & \\
\hline Hispanic & 2 & 5 & \\
\hline Other & 5 & 1 & \\
\hline Sexual Orientation & & & $\chi^{2}(2, N=416)=1.18$ \\
\hline Heterosexual & 195 & 207 & \\
\hline Homosexual & 4 & 2 & \\
\hline Bisexual & 3 & 5 & \\
\hline Marital Status & & & $\chi^{2}(2, N=415)=1.08$ \\
\hline Married & 7 & 4 & \\
\hline Not married & 183 & 199 & \\
\hline Cohabitating & 11 & 11 & \\
\hline Plan to Have Children & & & $\chi^{2}(2, N=414)=.59$ \\
\hline Yes & 188 & 195 & \\
\hline No & 13 & 18 & \\
\hline Mean political belief (SD) & $3.10(0.89)$ & $3.04(0.99)$ & $t(412)=.62$ \\
\hline Mean religiousness (SD) & $3.85(1.93)$ & $4.08(1.94)$ & $t(411)=-1.26$ \\
\hline Mean infant contact (SD) & $2.79(0.75)$ & $2.33(0.84)$ & $t(414.25)=5.87^{*}$ \\
\hline Mean child contact (SD) & $2.42(0.84)$ & $2.10(0.86)$ & $t(407)=3.83^{*}$ \\
\hline Mean infant liking (SD) & $2.84(0.95)$ & $2.22(0.95)$ & $t(413)=6.54^{*}$ \\
\hline Mean child liking (SD) & $2.74(1.00)$ & $2.24(1.02)$ & $t(412)=5.05^{*}$ \\
\hline
\end{tabular}

$*=p \leq .001$

Note. As explained in the text, a critical value of $p \leq .001$ was used throughout this study. 
Table 3. Comparison of Scale Scores for Male and Female Participants

\begin{tabular}{lcccccc}
\hline \multicolumn{4}{c}{ Gender } & & \multicolumn{2}{c}{ 95\% Confidence Interval } \\
\hline & Male & Female & $t$ & $d f$ & Lower & Upper \\
\hline Toy-Rating & $2.44(.64)$ & $2.14(.61)$ & $4.97^{*}$ & 415 & 0.18 & 0.43 \\
ASI-HS & $2.82(.85)$ & $2.42(.84)$ & $4.73^{*}$ & 415 & 0.23 & 0.56 \\
ASI-BS & $2.63(.70)$ & $2.52(.77)$ & 1.44 & 415 & -0.04 & 0.24 \\
MHS-GM & $38.03(11.19)$ & $30.67(11.02)$ & $6.76^{*}$ & 415 & 5.22 & 9.49 \\
\hline MHS-L & $37.37(10.63)$ & $31.33(11.37)$ & $5.60^{*}$ & 414.99 & 3.92 & 8.15 \\
HBQ-nurture & $34.24(21.54)$ & $29.24(19.45)$ & 2.49 & 415 & 0.01 & 0.12 \\
HBQ-nature & $47.53(22.01)$ & $49.49(19.49)$ & -.96 & 401.56 & -5.97 & 2.06 \\
PAQ-M & $21.85(3.86)$ & $20.46(3.88)$ & $3.65^{*}$ & 414 & 0.64 & 2.13 \\
\hline PAQ-F & $22.89(4.40)$ & $24.88(4.50)$ & $4.73^{*}$ & 414 & 0.14 & 0.35 \\
Neosexism & $3.39(.96)$ & $2.65(.82)$ & $8.50^{*}$ & 415 & 0.57 & 0.91 \\
SDO & $3.05(1.24)$ & $2.43(1.10)$ & $5.31^{*}$ & 415 & 0.12 & 0.26 \\
ImpTheory & $3.35(1.20)$ & $3.70(1.28)$ & -2.91 & 415 & -0.59 & -0.12 \\
\hline
\end{tabular}

Note. Toy-Rating = toy-rating task; ASI-HS = Ambivalent Sexism Inventory- Hostile Sexism; ASI-BS = Ambivalent Sexism Inventory- Benevolent Sexism; MHS-GM = Modern Homonegativity Scale- Gay Men; MHS-L = Modern Homonegativity Scale- Lesbians; HBQ-nuture = transformed Homosexuality Beliefs Questionnaire-Nurture; HBQ-nature = Homosexuality Beliefs Questionnaire-Nature; PAQ-F = transformed Personal Attributes Questionnaire-Feminine/Expressive; PAQ-M = modified Personal Attributes Questionnaire-Masculine/Instrumental; SDO = transformed Social Dominance Orientation; ImpTheory = Implicit Theory Measure. Standard deviations appear in parentheses after means. As explained in the text, a critical value of $p \leq .001$ was used throughout this study.

$*=p \leq .001$. 
Table 4. Correlations Between Scale Scores (Total Sample).

\begin{tabular}{|c|c|c|c|c|c|c|c|c|c|c|c|c|}
\hline & 1 & 2 & 3 & 4 & 5 & 6 & 7 & 8 & 9 & 10 & 11 & 12 \\
\hline $\begin{array}{l}\text { 1. Toy- } \\
\text { Rating }\end{array}$ & 1 & $.32 *$ & $.34^{*}$ & $.45 *$ & $.43 *$ & $.28 *$ & $-.26 *$ & .13 & .15 & $.36^{*}$ & $.26^{*}$ & .05 \\
\hline 2. ASI-HS & & 1 & $.28 *$ & $.44^{*}$ & $.42 *$ & $.25 *$ & $-.20 *$ & $.29 *$ & $.18^{*}$ & $.57 *$ & $.42 *$ & .10 \\
\hline 3. ASI-BS & & & 1 & $.39 *$ & $.37 *$ & $.30 *$ & $-.33^{*}$ & .12 & -.08 & $.21^{*}$ & $.27^{*}$ & .15 \\
\hline 4. MHS-GM & & & & 1 & $.93 *$ & $.43^{*}$ & $-.45 *$ & $.19 *$ & .14 & $.61^{*}$ & $.49 *$ & .12 \\
\hline 5. MHS-L & & & & & 1 & $.42 *$ & $-.43^{*}$ & $.18^{*}$ & .12 & $.58^{*}$ & $.48^{*}$ & .12 \\
\hline $\begin{array}{l}\text { 6. HBQ- } \\
\text { nurt }\end{array}$ & & & & & & 1 & $-.27^{*}$ & .07 & .14 & $.38 *$ & $.33 *$ & .01 \\
\hline 7. HBQ-nat & & & & & & & 1 & -.08 & .09 & $-.25 *$ & -.12 & .04 \\
\hline 8. PAQ-M & & & & & & & & 1 & -.08 & $.17^{*}$ & $.19 *$ & .07 \\
\hline 9. PAQ-F & & & & & & & & & 1 & $.27^{*}$ & $.26^{*}$ & -.02 \\
\hline $\begin{array}{l}10 . \\
\text { Neosexism }\end{array}$ & & & & & & & & & & 1 & $.56^{*}$ & .04 \\
\hline 11. SDO & & & & & & & & & & & 1 & $.16^{*}$ \\
\hline $\begin{array}{l}12 . \\
\text { ImpTheory }\end{array}$ & & & & & & & & & & & & 1 \\
\hline
\end{tabular}

Note. Toy-Rating = toy-rating task; ASI-HS = Ambivalent Sexism Inventory- Hostile Sexism; ASI-BS = Ambivalent Sexism Inventory- Benevolent Sexism; MHS-GM = Modern Homonegativity Scale- Gay Men; MHS-L = Modern Homonegativity Scale- Lesbians; HBQ-nurt = Homosexuality Beliefs QuestionnaireNurture; $\mathrm{HBQ}$-nat = Homosexuality Beliefs Questionnaire-Nature; PAQ-F = Personal Attributes Questionnaire-Feminine/Expressive; PAQ-M = Personal Attributes QuestionnaireMasculine/Instrumental; SDO = Social Dominance Orientation; ImpTheory = Implicit Theory Measure. As explained in the text, a critical value of $p<.001$ was used throughout this study. ${ }^{*}=p<.001$. 
Table 5. Correlations Between Scale Scores for Male Participants.

\begin{tabular}{|c|c|c|c|c|c|c|c|c|c|c|c|c|}
\hline & 1 & 2 & 3 & 4 & 5 & 6 & 7 & 8 & 9 & 10 & 11 & 12 \\
\hline $\begin{array}{l}\text { 1. Toy- } \\
\text { Rating }\end{array}$ & 1 & $.32 *$ & $.31^{*}$ & $.45^{*}$ & $.43^{*}$ & $.27^{*}$ & $-.26 *$ & .20 & .18 & $.32 *$ & $.20^{*}$ & .10 \\
\hline 2. ASI-HS & & 1 & $.25^{*}$ & $.59 *$ & $.57^{*}$ & $.24^{*}$ & $-.24 *$ & $.27^{*}$ & .05 & $.63^{*}$ & $.43^{*}$ & .15 \\
\hline 3. ASI-BS & & & 1 & $.40^{*}$ & $.35^{*}$ & .21 & $-.33^{*}$ & .16 & -.21 & .19 & .20 & .17 \\
\hline 4. MHS-GM & & & & 1 & $.91^{*}$ & $.38^{*}$ & $-.42 *$ & $.23^{*}$ & .13 & $.62 *$ & $.47^{*}$ & .20 \\
\hline 5. MHS-L & & & & & 1 & $.32 *$ & $-.39 *$ & .21 & .10 & $.60 *$ & $.45^{*}$ & .20 \\
\hline 6. HBQ-nurt & & & & & & 1 & -.18 & .12 & .18 & $.41^{*}$ & $.34 *$ & .02 \\
\hline 7. HBQ-nat & & & & & & & 1 & -.19 & .05 & $-.22 *$ & -.11 & .00 \\
\hline 8. PAQ-M & & & & & & & & 1 & -.10 & $.23^{*}$ & .17 & .05 \\
\hline 9. PAQ-F & & & & & & & & & 1 & .18 & .16 & .03 \\
\hline $\begin{array}{l}10 . \\
\text { Neosexism }\end{array}$ & & & & & & & & & & 1 & $.56^{*}$ & .11 \\
\hline 11. SDO & & & & & & & & & & & 1 & .21 \\
\hline $\begin{array}{l}12 . \\
\text { ImpTheory }\end{array}$ & & & & & & & & & & & & 1 \\
\hline
\end{tabular}

Note. Toy-Rating = toy-rating task; ASI-HS = Ambivalent Sexism Inventory- Hostile Sexism; ASI-BS = Ambivalent Sexism Inventory- Benevolent Sexism; MHS-GM = Modern Homonegativity Scale- Gay Men; MHS-L = Modern Homonegativity Scale- Lesbians; HBQ-nurt =transformed Homosexuality Beliefs Questionnaire-Nurture; HBQ-nat = Homosexuality Beliefs Questionnaire-Nature; PAQ-F =transformed Personal Attributes Questionnaire-Feminine/Expressive; PAQ-M = modified Personal Attributes Questionnaire-Masculine/Instrumental; SDO = transformed Social Dominance Orientation; ImpTheory = Implicit Theory Measure.

As explained in the text, a critical value of $p \leq .001$ was used throughout this study.

$*=p \leq .001$. 
Table 6. Correlations Between Scale Scores for Female Participants.

\begin{tabular}{|c|c|c|c|c|c|c|c|c|c|c|c|c|}
\hline & 1 & 2 & 3 & 4 & 5 & 6 & 7 & 8 & 9 & 10 & 11 & 12 \\
\hline $\begin{array}{l}\text { 1. Toy- } \\
\text { Rating }\end{array}$ & 1 & $.26^{*}$ & $.37 *$ & $.36^{*}$ & $.35^{*}$ & $.22^{*}$ & $-.25^{*}$ & -.01 & .03 & $.27 *$ & $.24^{*}$ & .11 \\
\hline 2. ASI-HS & & 1 & $.30 *$ & $.24 *$ & $.24^{*}$ & $.24^{*}$ & -.15 & .05 & .20 & $.44 *$ & $.36^{*}$ & .11 \\
\hline 3. ASI-BS & & & 1 & $.38 *$ & $.39 *$ & $.36^{*}$ & $-.32 *$ & .06 & -.01 & .21 & $.36^{*}$ & .16 \\
\hline 4. MHS-GM & & & & 1 & $.95^{*}$ & $.45^{*}$ & $-.49 *$ & .08 & .03 & $.49 *$ & $.40^{*}$ & .16 \\
\hline 5. MHS-L & & & & & 1 & $.47^{*}$ & $-.49 *$ & .08 & .04 & $.48^{*}$ & $.44^{*}$ & .15 \\
\hline 6. HBQ-nurt & & & & & & 1 & $-.35^{*}$ & .00 & .08 & $.31^{*}$ & $.33^{*}$ & .05 \\
\hline 7. HBQ-nat & & & & & & & 1 & .04 & .14 & $-.28 *$ & -.14 & .05 \\
\hline 8. PAQ-M & & & & & & & & 1 & -.14 & .00 & .10 & .14 \\
\hline 9. PAQ-F & & & & & & & & & 1 & $.23^{*}$ & $.28^{*}$ & .00 \\
\hline $\begin{array}{l}10 . \\
\text { Neosexism }\end{array}$ & & & & & & & & & & 1 & $.47^{*}$ & .10 \\
\hline 11. SDO & & & & & & & & & & & 1 & .20 \\
\hline $\begin{array}{l}12 . \\
\text { ImpTheory }\end{array}$ & & & & & & & & & & & & 1 \\
\hline
\end{tabular}

Note. Toy-Rating = toy-rating task; ASI-HS = Ambivalent Sexism Inventory- Hostile Sexism; ASI-BS = Ambivalent Sexism Inventory- Benevolent Sexism; MHS-GM = Modern Homonegativity Scale- Gay Men; MHS-L = Modern Homonegativity Scale- Lesbians; HBQ-nurt = transformed Homosexuality Beliefs Questionnaire-Nurture; HBQ-nat = Homosexuality Beliefs Questionnaire-Nature; $P A Q-F=$ transformed Personal Attributes Questionnaire-Feminine/Expressive; PAQ-M = modified Personal Attributes Questionnaire-Masculine/Instrumental; SDO = transformed Social Dominance Orientation; ImpTheory = Implicit Theory Measure.

As explained in the text, a critical value of $p \leq .001$ was used throughout this study.

$*=p \leq .001$. 
Table 7. Partial correlations of scale scores controlling for social desirability by participant gender.

\begin{tabular}{cccccccccccc}
\hline & & $\mathbf{1}$ & $\mathbf{2}$ & $\mathbf{3}$ & $\mathbf{4}$ & $\mathbf{5}$ & $\mathbf{6}$ & $\mathbf{7}$ & $\mathbf{8}$ & $\mathbf{9}$ & $\mathbf{1 0}$ \\
\hline Male & Toy-Rating & $.32^{*}$ & $.32^{*}$ & $.45^{*}$ & $.28^{*}$ & $-.27^{*}$ & .18 & .21 & .19 & $.32^{*}$ & -.20 \\
& & & & & & & & & & & \\
Female & Toy-Rating & $.25^{*}$ & $.37^{*}$ & $.36^{*}$ & .21 & $-.25^{*}$ & -.02 & .02 & $.22 *$ & $.27^{*}$ & $-.25^{*}$
\end{tabular}

Note . Toy-Rating = toy-rating task; 1 = Ambivalent Sexism Inventory- Hostile Sexism; 2 = Ambivalent Sexism Inventory- Benevolent Sexism; 3 = Combined Modern Homonegativity Scale; 4 = transformed Homosexuality Beliefs Questionnaire-Nurture; 5 = Homosexuality Beliefs Questionnaire-Nature; 6 = transformed Personal Attributes Questionnaire-Feminine/Expressive; 7 = modified Personal Attributes Questionnaire-Masculine/Instrumental; 8 = transformed Social Dominance Orientation; 9= Neosexism; $10=$ Big Five Inventory- Openness.

As explained in the text, a critical value of $p \leq .001$ was used throughout this study.

$*=p \leq .001$. 
Table 8. Partial Correlations, Controlled for Sex, Between Scale Scores and Toy-Rating Scores for Full Sample ( $\mathrm{N}=416)$.

\begin{tabular}{ccccc}
\hline Scale & All Toys & Male toys & Female Toys & Neutral Toys \\
\hline MHS & $.40^{*}$ & $.30^{*}$ & $.42^{*}$ & .05 \\
HBQ-nurture & $.25^{*}$ & $.22^{*}$ & $.21^{*}$ & .14 \\
ASI-HS & $.29 *$ & $.25^{*}$ & $.28^{*}$ & .02 \\
ASI-BS & $.34^{*}$ & $.29^{*}$ & $.31^{*}$ & .12 \\
PAQ-M & .09 & .08 & .07 & .10 \\
PAQ-F & .10 & .08 & .09 & .11 \\
\hline Neosexism & $.30 *$ & $.23^{*}$ & $.30^{*}$ & .08 \\
\hline SDO & $.22 *$ & $.19 *$ & $.20 *$ & \\
\hline
\end{tabular}

Note. ASI-HS = Ambivalent Sexism Inventory- Hostile Sexism; ASI-BS = Ambivalent Sexism InventoryBenevolent Sexism; MHS = Combined Modern Homonegativity Scale; HBQ-nuture = transformed Homosexuality Beliefs Questionnaire-Nurture; SDO = transformed Social Dominance Orientation; $\mathrm{PAQ}-\mathrm{F}=$ transformed Personal Attributes Questionnaire-Feminine/Expressive; $\mathrm{PAQ}-\mathrm{M}=$ modified Personal Attributes Questionnaire-Masculine/Instrumental As explained in the text, a critical value of $p \leq .001$ was used throughout this study.

$*=p \leq .001$. 
Table 9. Partial Correlations, Controlled for Sex, Between Scale Scores and Toy-Rating Scores for Prospective Parent Sample ( $\mathrm{N}=379)$.

\begin{tabular}{ccccc}
\hline Scale & All Toys & Male toys & Female Toys & Neutral Toys \\
\hline MHS & $.40^{*}$ & $.29^{*}$ & $.42^{*}$ & .04 \\
HBQ-nurture & $.24^{*}$ & $.21^{*}$ & $.21^{*}$ & .09 \\
ASI-HS & $.33^{*}$ & $.28^{*}$ & $.32^{*}$ & .09 \\
ASI-BS & $.33^{*}$ & $.27^{*}$ & $.32^{*}$ & .08 \\
PAQ-M & .09 & .07 & .08 & .03 \\
PAQ-F & .12 & .11 & .11 & .12 \\
\hline Neosexism & $.29 *$ & $.22^{*}$ & $.30^{*}$ & .08 \\
\hline SDO & $.23^{*}$ & $.20^{*}$ & $.22^{*}$ & \\
\hline
\end{tabular}

Note. ASI-HS = Ambivalent Sexism Inventory- Hostile Sexism; ASI-BS = Ambivalent Sexism InventoryBenevolent Sexism; MHS = Combined Modern Homonegativity Scale; HBQ-nuture = transformed Homosexuality Beliefs Questionnaire-Nurture; SDO = transformed Social Dominance Orientation; PAQ-F = transformed Personal Attributes Questionnaire-Feminine/Expressive; PAQ-M = modified Personal Attributes Questionnaire-Masculine/Instrumental

As explained in the text, a critical value of $p \leq .001$ was used throughout this study.

$*=p \leq .001$. 
Table 10. Summary of Multiple Regression Analyses for Variables Predicting Gender-Typed Toy Ratings ( $\mathrm{N}=416)$

\begin{tabular}{ccccc}
\hline Variable & $B$ & SE B & $\beta$ & $\mathrm{t}$ \\
Sex & -.14 & .06 & -.11 & -2.26 \\
ASI-HS & .08 & .04 & .10 & 1.91 \\
ASI-BS & .17 & .04 & $.20^{*}$ & 4.12 \\
MHS & .01 & .00 & $.24^{*}$ & 4.13 \\
HBQ- & .12 & .12 & .05 & 1.08 \\
nurture & & & & \\
Neosexism & .05 & .04 & .07 & 1.15 \\
SDO & -.08 & .09 & -.05 & -.83 \\
$\boldsymbol{R}^{2}$ & & & & .26 \\
$\boldsymbol{F}$ & & & & 20.75 \\
\hline
\end{tabular}

Note. ASI-HS = Ambivalent Sexism Inventory- Hostile Sexism; ASI-BS = Ambivalent Sexism InventoryBenevolent Sexism; MHS = Combined Modern Homonegativity Scale; HBQ-nuture = transformed Homosexuality Beliefs Questionnaire-Nurture; SDO = transformed Social Dominance Orientation; As explained in the text, a critical value of $p \leq .001$ was used throughout this study.

$*=p \leq .001$. 
Table 11. Correlations Between the Big Five Inventory Subscales and Toy-Rating Scores.

\begin{tabular}{lccccc}
\hline & Extraversion & Agreeableness & Conscientiousness & Neuroticism & Openness \\
\hline $\begin{array}{l}\text { Toy- } \\
\text { Rating }\end{array}$ & .04 & -.09 & .03 & -.07 & $-.21^{*}$ \\
\hline
\end{tabular}

As explained in the text, a critical value of $p<.001$ was used throughout this study.

$*=p \leq .001$. 
Figure 1. Results of Combined Cluster Analysis.

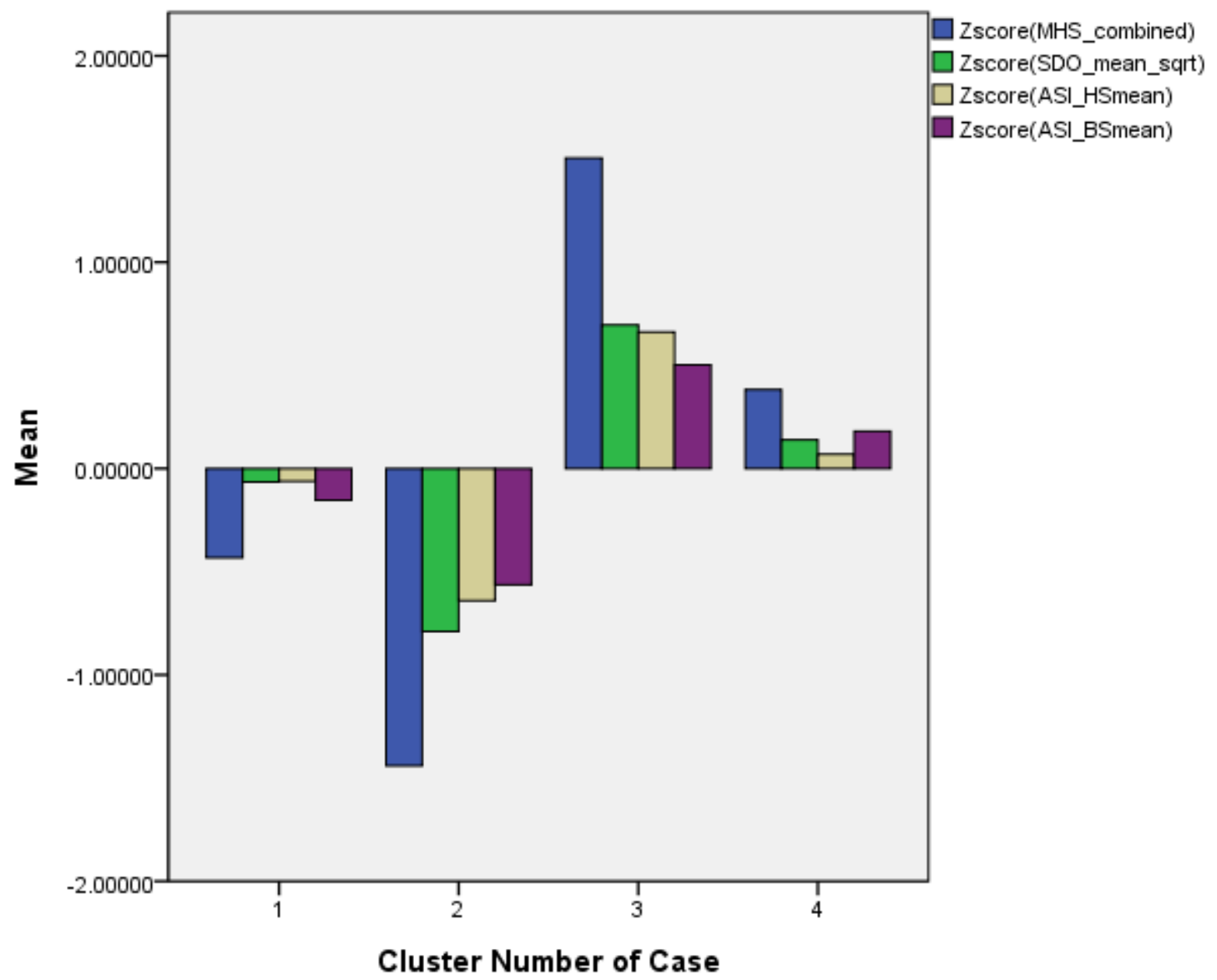


Figure 2. Results of Male-Only Cluster Analysis

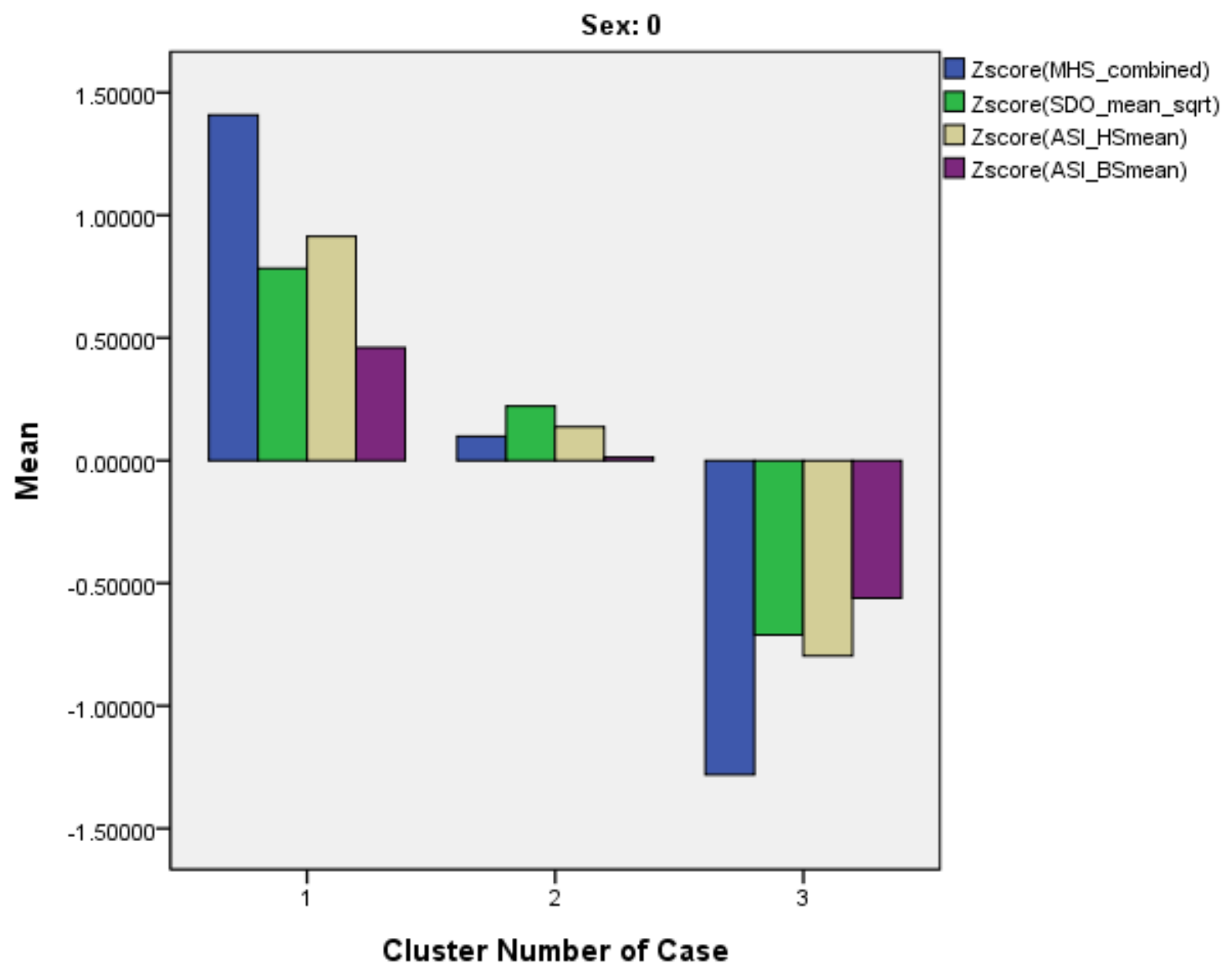


Figure 3. Results of Female-Only Cluster Analysis

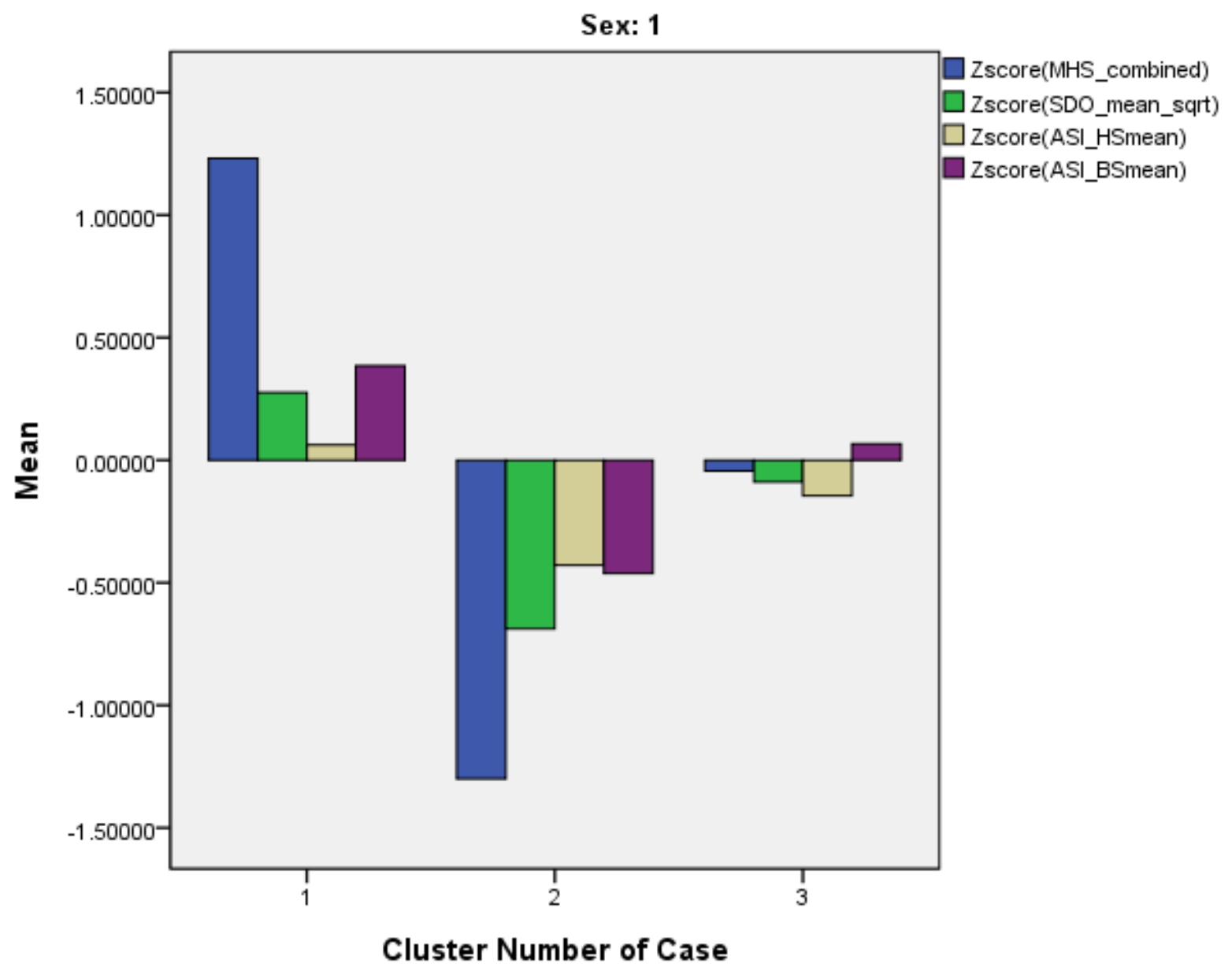

